\title{
Hepatic Organic Anion Transporting Polypeptide-Mediated Clearance in the Beagle Dog: Assessing In Vitro-In Vivo Relationships and Applying Cross-Species Empirical Scaling Factors to Improve Prediction of Human Clearance ${ }^{\mathbb{S}}$
}

\author{
Norikazu Matsunaga, Ayşe Ufuk, Bridget L. Morse, David W. Bedwell, Jingqi Bao, \\ Michael A. Mohutsky, Kathleen M. Hillgren, Stephen D. Hall, J. Brian Houston, \\ and Aleksandra Galetin
}

Centre for Applied Pharmacokinetic Research, University of Manchester, Manchester, United Kingdom (N.M., A.U., J.B.H., A.G.); Pharmacokinetic Research Laboratories, Ono Pharmaceutical Co., Ltd., Osaka, Japan (N.M.); and Lilly Research Laboratories, Eli Lilly and Company, Indianapolis, Indiana (B.L.M., D.W.B., J.B., M.A.M., K.M.H., S.D.H.)

Received August 24, 2018; accepted December 17, 2018

\section{ABSTRACT}

In the present study, the beagle dog was evaluated as a preclinical model to investigate organic anion transporting polypeptide (OATP)mediated hepatic clearance. In vitro studies were performed with nine OATP substrates in three lots of plated male dog hepatocytes \pm OATP inhibitor cocktail to determine total uptake clearance $\left(\mathrm{CL}_{\text {uptake }}\right)$ and total and unbound cell-to-medium concentration ratio $\left(\mathrm{Kp}_{\mathrm{uu}}\right)$. In vivo intrinsic hepatic clearances $\left(\mathrm{CL}_{\mathrm{int}, \mathrm{H}}\right)$ were determined following intravenous drug administration $(0.1 \mathrm{mg} / \mathrm{kg})$ in male beagle dogs. The in vitro parameters were compared with those previously reported in plated human, monkey, and rat hepatocytes; the ability of crossspecies scaling factors to improve prediction of human in vivo clearance was assessed. $C_{\text {uptake }}$ in dog hepatocytes ranged from 9.4 to $135 \mu \mathrm{l} / \mathrm{min} / 10^{6}$ cells for fexofenadine and telmisartan, respectively. Active process contributed $>75 \%$ to $\mathrm{CL}_{\text {uptake }}$ for $5 / 9$ drugs.
Rosuvastatin and valsartan showed $\mathrm{Kp}_{\mathrm{uu}}>10$, whereas cerivastatin, pitavastatin, repaglinide, and telmisartan had $\mathrm{Kp}_{\mathrm{uu}}<5$. The extent of hepatocellular binding in dog was consistent with other preclinical species and humans. The bias (2.73-fold) obtained from comparison of predicted versus in vivo dog $\mathrm{CL}_{i n t, H}$ was applied as an average empirical scaling factor $\left(E S F_{\text {av }}\right)$ for in vitro-in vivo extrapolation of

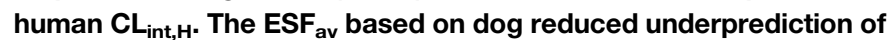
human $\mathrm{CL}_{\text {int }, \mathrm{H}}$ for the same data set (geometric mean fold error $=2.1$ ), highlighting its utility as a preclinical model to investigate OATPmediated uptake. The $\mathrm{ESF}_{\mathrm{av}}$ from all preclinical species resulted in comparable improvement of human clearance prediction, in contrast to drug-specific empirical scalars, rationalized by species differences in expression and/or relative contribution of particular transporters to drug hepatic uptake.
Introduction

For many acidic or zwitterionic drugs, transporter-mediated uptake clearance is an important contributor to hepatic disposition and can be a rate-determining process for drug hepatic clearance and corresponding drug-drug interactions (DDIs) (Gertz et al., 2013; Shitara et al., 2013; Zamek-Gliszczynski et al., 2013; Varma et al., 2015). The value of in vitro-derived transporter kinetic data within a physiologically based pharmacokinetic (PBPK) paradigm is now widely appreciated (Jones et al., 2015; Galetin et al., 2017; Yoshida et al., 2017; Guo et al., 2018),

This work was supported by a consortium of pharmaceutical companies (GlaxoSmithKline, Lilly, and Pfizer) within the Centre for Applied Pharmacokinetic Research at the University of Manchester.

https://doi.org/10.1124/dmd.118.084194.

S This article has supplemental material available at dmd.aspetjournals.org. yet prediction success is still limited. Robust studies using preclinical animals to increase confidence in the subsequent application of in vitroin vivo extrapolation (IVIVE) of human in vitro transporter data (De Bruyn et al., 2018) would help alleviate this shortcoming.

Recently, we demonstrated the utility of the cynomolgus monkey as a preclinical species for evaluation of organic anion transporting polypeptide (OATP)-mediated hepatic clearance and DDIs (De Bruyn et al., 2018; Ufuk et al., 2018). Despite an overall good relationship between in vitro-derived clearance in cynomolgus monkey hepatocytes and in vivo clearance in the same species, the underprediction trend was apparent. The bias correction noted for the cynomolgus monkey clearance prediction was subsequently applied as an empirical scaling factor (ESF) to improve the prediction of human hepatic clearance for the same OATP substrates from human hepatocytes. The success of the crossspecies scaling approach based on cynomolgus monkey may be linked to the excellent agreement with humans in OATP protein sequence

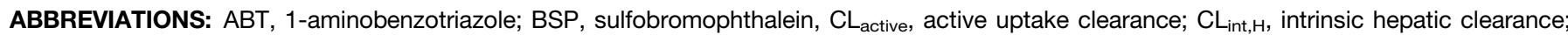

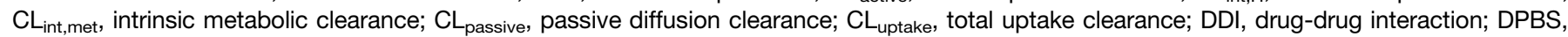

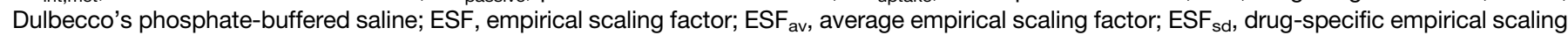
factor; fu cell, fraction unbound in cells; gmfe, geometric mean fold error; IVIVE, in vitro-in vivo extrapolation; Kp, total cell-to-medium concentration ratio; $\mathrm{Kp}_{\mathrm{uu}}$, cell-to-medium concentration ratio for unbound drug; LC-MS/MS, liquid chromatography with tandem mass spectrometry; OATP/Oatp, organic anion transporting polypeptide; P450, cytochrome P450; PBPK, physiologically based pharmacokinetic. 
homology. This work was extended to include two widely used preclinical species, the beagle dog and Sprague-Dawley rat, for which OATP proteomics is less well defined but believed to show poor homology with humans.

An increasing number of studies have recently investigated hepatic uptake transporter-mediated clearance and DDIs in cynomolgus monkeys, both in vitro and in vivo (Shen et al., 2013; Chu et al., 2015; De Bruyn et al., 2018; Ufuk et al., 2018). In contrast, there is minimal information on or systematic evaluation of activity of hepatic transporters in beagle dogs (Wilby et al., 2011). Studies in rats have been limited to hepatocyte investigations, and predictions of in vivo clearance have been inconsistent (Huang et al., 2010; Wood et al., 2017). Recent protein quantification by mass spectrometry has revealed interspecies differences in absolute expression levels of hepatobiliary transporters in the liver and drugmetabolizing enzymes in various species (Heikkinen et al., 2015; Wang et al., 2015). Canine Oatp1b4 is the most abundant transporter and represents approximately half of the total abundance of hepatobiliary transporters in dog liver, in contrast to human OATP1B1 and OATP1B3, which contribute only approximately $29 \%$ to the total abundance of hepatic transporters expressed in human liver (Wang et al., 2015). Oatp1a1, Oatp1a4, and Oatp1b2 are major Oatp transporters expressed on the sinusoidal membrane of rat hepatocytes (Wang et al., 2015). In cynomolgus monkeys, Oatp1b1 and Oatp1b3 are mainly expressed in the liver (Wang et al., 2015), showing a high level of amino acid homology $(>90 \%)$ between human and cynomolgus monkey transporter counterparts (Shen et al., 2013). In the case of beagle dogs, Oatp1b4 shows $68 \%$ and $71 \%$ homology at protein level to human OATP1B1 and OATP1B3, respectively (Gui and Hagenbuch, 2010).

To date, limited in vitro and in vivo data have been reported in the beagle dog for OATP-mediated hepatic clearances, and examples of IVIVE of transporter-mediated hepatic clearance in this preclinical species are few. Here, we report the in vitro characterization of hepatic uptake for nine known OATP substrates (namely, atorvastatin, cerivastatin, fexofenadine, pitavastatin, pravastatin, repaglinide, rosuvastatin, telmisartan, and valsartan) in plated male dog hepatocytes $+/$ - cocktail of OATP inhibitors. Based on data in other preclinical species and humans, selected OATP substrates cover a range of low to high clearance drugs with different contributions of active versus passive processes to the overall hepatic clearance. In addition to in vitro studies, in vivo pharmacokinetic studies were conducted in beagle dogs following intravenous drug administration to evaluate hepatic clearance prediction by IVIVE. The use of dog ESFs to refine prediction of human clearance was explored, as recently reported for data obtained in cynomolgus monkey hepatocytes (De Bruyn et al., 2018). Dataset average and individual drug specific ESFs $\left(\mathrm{ESF}_{\mathrm{av}}\right.$ and $\mathrm{ESF}_{\mathrm{sd}}$, respectively) were derived from the relationship between in vivo and in vitro predicted clearance in beagle dog, were determined. A similar exercise was performed for the rat using previously published hepatocyte kinetic data derived under experimental conditions (Ménochet et al., 2012a; Cantrill and Houston, 2017) similar to those reported here for the dog studies. Furthermore, in vitro-derived parameters were compared across all preclinical species investigated. The extent of improvement in human clearance prediction based on application of ESFs from beagle dog was compared with the application of ESFs from monkey and rat data for the same data set of OATP substrates.

\section{Materials and Methods}

Chemicals. 1-Aminobenzotriazole (ABT), atorvastatin, fexofenadine, pravastatin, repaglinide, rifamycin SV, and sulfobromophthalein (BSP) were purchased from Sigma-Aldrich (Poole, UK). Atorvastatin lactone, repaglinide acyl- $\beta$-Dglucuronide, and telmisartan acyl- $\beta$-D-glucuronide were purchased from Toronto Research Chemicals Inc. (North York, Canada). Cerivastatin, pitavastatin, rosuvastatin, and valsartan were purchased from Sequoia Research Products (Pangbourne, UK). For in vivo studies, atorvastatin, telmisartan, and rosuvastatin were purchased from Thermo Fisher Scientific (Waltham, MA). Pitavastatin and repaglinide were purchased from Selleck Chemicals (Houston, TX). Fexofenadine and pravastatin were purchased from TCI America (Portland, OR). Valsartan was purchased from Sigma-Aldrich (St. Louis, MO). Cerivastatin was purchased from Ochem Incorporation (Des Plaines, IL).

Hepatocyte Uptake Studies. Cryopreserved male beagle dog hepatocytes (lots XVD, XZG, and YHF, all single donors) were purchased from BioIVT (Baltimore, MD). Cryopreserved dog hepatocytes were thawed according to the manufacturer's standard protocol, and $0.5 \mathrm{ml}$ of suspended hepatocytes $\left(0.7 \times 10^{6}\right.$ viable cells $/ \mathrm{ml}$ ) was added to each well of collagen I-coated BioCoat 24-well plates (BD Biosciences, Bedford, MA). After 4-hour culturing in a $\mathrm{CO}_{2}$ incubator, the medium was discarded, and the cell monolayers were preincubated with Dulbecco's phosphate-buffered saline (DPBS) containing $1 \mathrm{mM} \mathrm{ABT}+/$ - OATP inhibitor cocktail (100 $\mu \mathrm{M}$ rifamycin SV and $50 \mu \mathrm{M}$ BSP) for 30 minutes. ABT was used as a pan-inhibitor to inactivate cytochrome P450 (P450) activities in dog hepatocytes. Uptake data in the presence of OATP inhibitor cocktail were used to determine the passive diffusion clearance $\left(\mathrm{CL}_{\text {passive }}\right)$ value. This approach was based on preliminary data that showed more pronounced inhibition of uptake of the prototypical OATP probes pitavastatin and repaglinide in dog hepatocytes compared with the use of rifamycin SV or BSP alone (data not shown). Subsequently, uptake was started by adding fresh DPBS containing OATP substrate at a concentration of $0.5 \mu \mathrm{M}$ (with the exception of pravastatin, $5 \mu \mathrm{M}$ ) $+/$ - OATP inhibitor cocktail and over $2 \mathrm{~min}$ at $37^{\circ} \mathrm{C}$. The buffer was collected, and $200 \mu \mathrm{l}$ of water was added to lyse the cells after washing the cells with icecooled DPBS three times. All uptake experiments were performed in triplicate. In addition, extended uptake studies over 90 minutes (with up to eight time points) were performed to reach equilibrium and determine the total cell-to-medium drug concentration ratio $(\mathrm{Kp})$; the same low drug concentration was used as in shorter incubations. Any potential cell loss was accounted for by measuring protein concentrations in cell lysates using the bicinchoninic acid assay according to the manufacturer's protocol (Life Technologies Ltd., Paisley, UK). Drug concentrations in cell lysate and medium were quantified by liquid chromatography with tandem mass spectrometry (LC-MS/MS); conditions are detailed in Supplemental Table S1. In addition, the metabolism of atorvastatin to atorvastatin lactone (Prueksaritanont et al., 2002) and repaglinide and telmisartan to their respective acyl-glucuronides (Gill et al., 2012; Säll et al., 2012) was monitored.

Determination of Plasma Protein Binding. Fraction unbound in dog plasma $\left(\mathrm{fu}_{\mathrm{p}}\right)$ was determined for all compounds via equilibrium dialysis at a concentration of $1 \mu \mathrm{M}$. In brief, presoaked dialysis membranes were placed in a 96-well microequilibrium dialysis device, then $125 \mu \mathrm{l}$ of plasma spiked with compound was loaded opposite to $100 \mu \mathrm{l}$ of $100 \mathrm{mM}$ sodium phosphate buffer ( $\mathrm{pH} 7.4$ ) in triplicate. Plates were sealed and incubated at $37^{\circ} \mathrm{C}$ with $5 \% \mathrm{CO}_{2}$ for 4 hours, shaking at $200 \mathrm{rpm}$, after which $25 \mu \mathrm{l}$ of plasma/buffer was taken and mixed with $25 \mu \mathrm{l}$ of buffer/plasma. The $50 \mu \mathrm{l}$ samples were then quenched with $150 \mu \mathrm{l}$ of acetonitrile containing internal standard for the individual compound, and concentrations were quantified via LC-MS/MS, as described in Supplemental Table S2. Recovery over the 4-hour period was tested for all compounds and ranged from $97 \%$ to $108 \%$.

In Vivo Studies. In vivo study protocol was reviewed and approved by the Institutional Animal Care and Use Committee. Male beagle dogs $(n=3 /$ study arm) weighed 8-15 kg at the time of study conduct and were fasted overnight prior to being administered compound. All compounds were intravenously administered at $0.1 \mathrm{mg} / \mathrm{kg}$ as a $20 \%$ captisol solution and were given over 30 minutes via a temporary catheter inserted into the cephalic vein. Blood samples were taken from the jugular vein at $0.25,0.42,0.58,0.75,1,1.5,2.5,4.5,8.5,12.5$, and 24.5 hours following administration. Blood samples were collected in tubes containing EDTA and centrifuged to collect plasma. Studies were carried out in cages with plexiglass surroundings for collection of urine from 0 to 4,4 to 8,8 to 12, and 12 to 24 hours. Additional blood samples were taken at predose, 4, 8, 12 , and 24 hours for measurement of plasma creatinine. Creatinine was also measured in an aliquot from each urine collection interval. Plasma and urine samples for determination of compound concentrations were stored at $\leq-20^{\circ} \mathrm{C}$ until analysis via LC-MS/MS, as described in Supplemental Table S2.

Analysis of In Vitro Hepatocyte Data. In vitro uptake rates (pmol/min/mg protein) were calculated from the slopes of the initial uptake rate-time profile in 
the absence and presence of OATP inhibitor cocktail; the rates were then divided by the initial substrate concentration to determine total uptake clearance $\left(\mathrm{CL}_{\text {uptake }}, \mu \mathrm{l} / \mathrm{min} / \mathrm{mg}\right.$ protein) and $\mathrm{CL}_{\text {passive }}(\mu 1 / \mathrm{min} / \mathrm{mg}$ protein), respectively (Yabe et al., 2011). Passive influx diffusion clearance was assumed to be equal to the passive efflux, and effect of membrane potential (Yoshikado et al., 2017) was not considered. Adsorption of the drug to the plate in the absence of cells was $<7 \%$ across all substrates investigated, regardless of the presence of OATP inhibitor cocktail. In vitro hepatic active uptake clearance $\left(\mathrm{CL}_{\text {active }}\right)$ was calculated by subtracting the $\mathrm{CL}_{\text {passive }}$ from the $\mathrm{CL}_{\text {uptake }}$ (Yabe et al., 2011). The conversion of $\mathrm{CL}_{\text {uptake }}, \mathrm{CL}_{\text {passive, }}$, and $\mathrm{CL}_{\text {active }}$ to $\mu \mathrm{L} / \mathrm{min} / 10^{6}$ cells was carried out using $1.2 \mathrm{mg}$ of protein $/ 10^{6} \mathrm{dog}$ hepatocytes based on in-house data generated using the bicinchoninic acid assay (data not shown). The $\mathrm{CL}_{\text {passive }}$ was $\log$ transformed and compared with the $\log \mathrm{D}_{7.4}$ values of the drugs investigated, taken from a previous study (Yabe et al., 2011). The Kp parameter, which represents intracellular binding in addition to active uptake processes, was calculated from eq. 1 :

$$
\mathrm{Kp}=C_{\text {cell }} / C_{\text {medium }}
$$

where $C_{\text {cell }}$ and $C_{\text {medium }}$ represent drug concentrations in cells and medium, respectively. The hepatocyte volume was set to $3.9 \mu 1 / 10^{6}$ hepatocytes with an assumption of the same volume as reported in rats (Reinoso et al., 2001). The cell-to-medium concentration ratio for unbound drug $\left(\mathrm{Kp}_{\mathrm{uu}}\right)$ was calculated from eq. 2 (Yabe et al., 2011; Shitara et al., 2013):

$$
\mathrm{Kp}_{\text {uu }}=\mathrm{CL}_{\text {uptake }} /\left(\mathrm{CL}_{\text {passive }}+\mathrm{CL}_{\text {int }}\right)
$$

where $\mathrm{CL}_{\mathrm{int}}$ represents intrinsic clearance for either metabolism and/or biliary excretion. Cerivastatin, fexofenadine, pitavastatin, pravastatin, rosuvastatin, and valsartan are metabolically stable or metabolized mainly by P450. Metabolic clearance was assumed negligible for these drugs because ABT, a pan-P450 inhibitor, was included in the incubations. The biliary excretion of all the drugs investigated was considered negligible under the current experimental setup due to internalization of efflux transporters following short-term culturing (Bow et al., 2008). The formation of atorvastatin lactone, repaglinide, and telmisartan glucuronides was not negligible under prolonged incubation times used to determine the $\mathrm{Kp}$. Therefore, intrinsic metabolic clearance $\left(\mathrm{CL}_{\mathrm{int}, \mathrm{met}}\right)$ was calculated from the slope of the linear phase of metabolite formation over time, and these $\mathrm{CL}_{\text {int,met }}$ values were used to calculate the $\mathrm{Kp}_{\mathrm{uu}}$ of atorvastatin, repaglinide, and telmisartan using eq. 2 . The fraction unbound in the cell $\left(\mathrm{fu}_{\mathrm{cell}}\right)$ was calculated indirectly using eq. 3 (Yabe et al., 2011):

$$
\mathrm{fu}_{\text {cell }}=\mathrm{Kp}_{\mathrm{uu}} / \mathrm{Kp}
$$

In addition to the analysis of the initial uptake rate data, the $\mathrm{fu}_{\text {cell }}, \mathrm{CL}_{\mathrm{active}}$, and $\mathrm{CL}_{\text {passive }}$ were determined by simultaneous fitting of uptake data over an extended time course in the absence and presence of OATP inhibitor cocktail. An adaptation of the mechanistic two-compartment model (Ménochet et al., 2012b) in MATLAB (version 8.5.1, 2015; MathWorks, Natick, MA) was applied to estimate $\mathrm{CL}_{\text {active, }}$, $\mathrm{CL}_{\text {passive, }}$, and $\mathrm{fu}_{\text {cell }}$ under the assumption that $\mathrm{CL}_{\text {active }}$ in eqs. 4 and 5 approaches zero in the presence of transporter inhibitors. As a proof of concept, this method was only applied for six drugs that do not undergo metabolism under the experimental conditions used (cerivastatin, fexofenadine, pitavastatin, pravastatin, rosuvastatin, and valsartan) and using lot XVD of dog hepatocytes:

$$
\begin{aligned}
\frac{d S_{\text {cell }}}{d t} & =\frac{\left(\mathrm{CL}_{\text {active }}+\mathrm{CL}_{\text {passive }}\right) \times S_{\text {med }}-\mathrm{CL}_{\text {passive }} \times S_{\text {cell }} \times \mathrm{fu}_{\text {cell }}}{V_{\text {cell }}} \\
\frac{d S_{\text {med }}}{d t} & =\frac{-\left(\mathrm{CL}_{\text {active }}+\mathrm{CL}_{\text {passive }}\right) \times S_{\text {med }}+\mathrm{CL}_{\text {passive }} \times S_{\text {cell }} \times \mathrm{fu}_{\text {cell }}}{V_{\text {med }}}
\end{aligned}
$$

where $S_{\text {cell }}$ and $S_{\text {med }}$ represent the intracellular and media drug concentrations, respectively; and $V_{\text {cell }}$ and $V_{\text {med }}$ are the intracellular and media volumes, which were set at 3.9 and $400 \mu 1$, respectively.

Analysis of In Vivo Dog Data. In vivo data were analyzed using Watson LIMS 7.5 (Thermo Fisher Scientific). Systemic in vivo plasma clearance $\left(\mathrm{CL}_{\text {total }}\right)$ was determined using eq. 6 :

$$
\mathrm{CL}_{\text {total }}=\frac{\text { dose }}{\mathrm{AUC}_{0-\infty}}
$$

where $\mathrm{AUC}_{0-\infty}$ represents the extrapolated area under the plasma concentrationtime curve. For compounds with measurable urinary excretion, renal clearance $\left(\mathrm{CL}_{\mathrm{R}}\right)$ was determined with eq. 7 :

$$
\mathrm{CL}_{\mathrm{R}}=\frac{\mathrm{Ae}_{0-24}}{\mathrm{AUC}_{0-24}}
$$

where $\mathrm{Ae}_{0-24}$ and $\mathrm{AUC}_{0-24}$ represent the amount excreted in the urine and the area under the plasma concentration-time curve from 0 to 24 hours, respectively. To account for possible incomplete urine collection, $C L_{R}$ was corrected for recovery of creatinine in the urine. $\mathrm{CL}_{\mathrm{R}}$ for creatinine was calculated as shown in eq. 7 , and corrected $\mathrm{CL}_{\mathrm{R}}$ for drugs investigated was obtained as shown in eq. 8:

$$
\text { corrected } \mathrm{CL}_{\mathrm{R}}=\mathrm{CL}_{\mathrm{R}} \div \frac{\text { creatinine } \mathrm{CL}_{\mathrm{R}}}{\mathrm{GFR}}
$$

where GFR represents reported glomerular filtration rate in dogs of $3.2 \mathrm{ml} / \mathrm{min} / \mathrm{kg}$ (Mahmood, 1998).

In addition to creatinine, plasma iohexol clearance was measured, and values obtained were comparable to creatinine clearance (data not shown). In vivo hepatic clearance $\left(\mathrm{CL}_{\mathrm{H}}\right)$ was calculated by subtracting $\mathrm{CL}_{\mathrm{R}}$ from $\mathrm{CL}_{\text {total }}$.

Extrapolation of In Vitro Hepatic Uptake Clearance to In Vivo. The IVIVE method was based on the overall uptake clearance parameter, and therefore, net effect of multiple processes was captured. Dog in vitro $\mathrm{CL}_{\text {uptake }} \mu \mathrm{L} / \mathrm{min} / 10^{6}$ cells was scaled by a hepatocellularity value of $175 \times 10^{6}$ cells/g of liver and average dog liver weight of $32 \mathrm{~g}$ of liver/body weight. A median value of hepatocellularity values

\begin{tabular}{|c|c|c|c|c|}
\hline Drugs & $\mathrm{CL}_{\text {uptake }}$ & $\mathrm{CL}_{\text {passive }}$ & $\mathrm{CL}_{\text {active }}$ & Active Contribution \\
\hline & $\mu \mathrm{l} / \mathrm{min} / 10^{6} \mathrm{cells}$ & $\mu \mathrm{l} / \mathrm{min} / 10^{6}$ cells & $\mu \mathrm{l} / \mathrm{min} / 10^{6}$ cells & $\%$ \\
\hline Atorvastatin & $107 \pm 28$ & $12.8 \pm 1.5$ & $94.6 \pm 27.7$ & $87.6 \pm 2.7$ \\
\hline Cerivastatin & $143 \pm 57$ & $44.9 \pm 23.7$ & $98.5 \pm 35.8$ & $69.2 \pm 6.1$ \\
\hline Fexofenadine & $9.44 \pm 5.47$ & $2.41 \pm 2.24$ & $7.03 \pm 6.11$ & $68.8 \pm 23.4$ \\
\hline Pitavastatin & $112 \pm 44$ & $29.4 \pm 7.4$ & $82.5 \pm 40.0$ & $71.1 \pm 11.2$ \\
\hline Pravastatin & $9.77 \pm 3.24$ & $1.28 \pm 0.78$ & $8.50 \pm 3.36$ & $86.2 \pm 9.9$ \\
\hline Repaglinide & $135 \pm 44$ & $37.0 \pm 10.0$ & $98.1 \pm 35.7$ & $72.0 \pm 5.8$ \\
\hline Rosuvastatin & $24.0 \pm 1.7$ & $1.91 \pm 0.52$ & $22.0 \pm 2.1$ & $91.9 \pm 2.6$ \\
\hline Telmisartan & $135 \pm 33$ & $32.7 \pm 9.1$ & $102 \pm 26$ & $75.5 \pm 4.2$ \\
\hline Valsartan & $30.3 \pm 3.4$ & $1.37 \pm 0.65$ & $28.9 \pm 3.7$ & $95.4 \pm 2.6$ \\
\hline
\end{tabular}
reported in the literature for beagle dogs was used (details of data collation in Supplemental Table S3). In vivo intrinsic hepatic clearance $\left(\mathrm{CL}_{\mathrm{int}, \mathrm{H}} ; \mathrm{mL} / \mathrm{min} / \mathrm{kg}\right)$ was obtained by applying the well stirred model (eq. 9):

$$
\mathrm{CL}_{\mathrm{int}, \mathrm{H}}=\frac{\mathrm{CL}_{\mathrm{H}}}{\frac{f_{u}}{\mathrm{R}_{\mathrm{B}}} \times\left(1-\frac{\mathrm{CL}_{\mathrm{H}}}{\mathrm{Q}_{\mathrm{H}}}\right)}
$$

TABLE 1

Uptake parameters of nine drugs investigated in dog hepatocytes

Data represent the mean \pm S.D. from three lots of dog hepatocytes. 

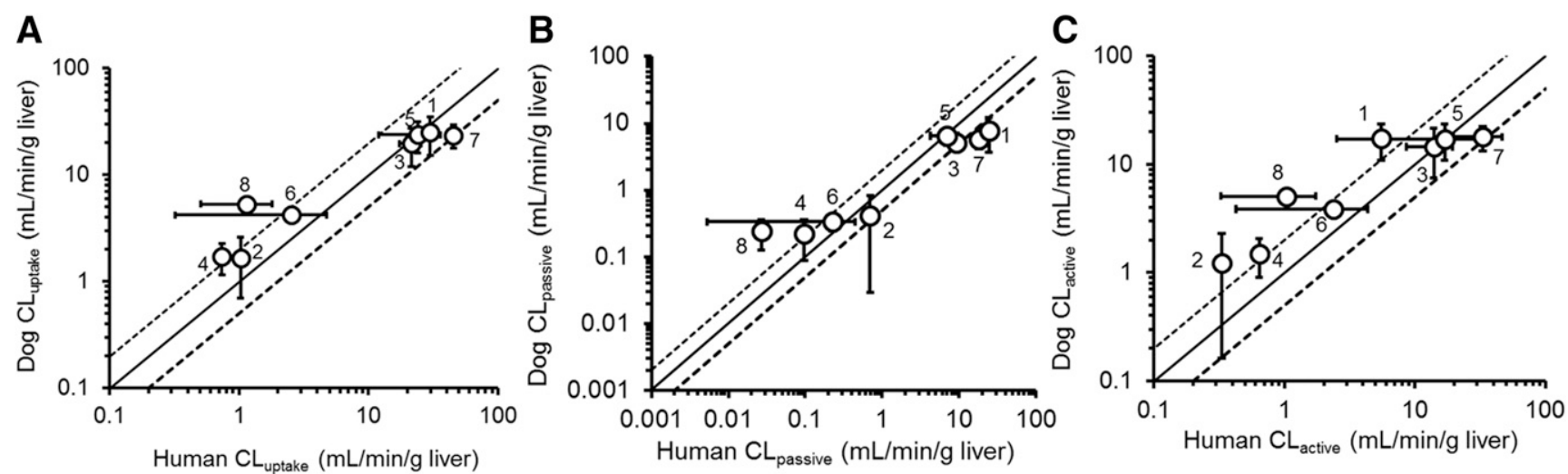

Fig. 1. Comparison of uptake parameters between humans and dogs. $\mathrm{CL}_{\text {uptake }}(\mathrm{A}), \mathrm{CL}_{\text {passive }}(\mathrm{B})$, and $\mathrm{CL}_{\text {active }}(\mathrm{C})$ in plated dog hepatocytes scaled to per gram of liver were compared with those in plated human hepatocytes (Ménochet et al., 2012b; De Bruyn et al., 2018). Data represent the mean \pm S.D. of $n=3$ dog hepatocyte donors. In human hepatocytes, data represent the mean \pm S.D. of $n=4$ donors (details in Supplemental Table S9 footnote). The solid and dashed lines represent the line of unity and 2-fold difference, respectively. 1 , cerivastatin; 2 , fexofenadine; 3 , pitavastatin; 4, pravastatin; 5 , repaglinide; 6 , rosuvastatin; 7 , telmisartan; 8 , valsartan.

where $\mathrm{Q}_{\mathrm{H}}$ represents average hepatic blood flow in beagle dog of $40 \mathrm{ml} / \mathrm{min} / \mathrm{kg}$ (summary of individual studies reported in the literature is in Supplemental Table $\mathrm{S} 3$ ), and $\mathrm{R}_{\mathrm{B}}$ represents blood-to-plasma ratio. For atorvastatin, the $\mathrm{CL}_{\mathrm{H}}$ corrected by the $\mathrm{R}_{\mathrm{B}}$ value was greater than $\mathrm{Q}_{\mathrm{H}}$; therefore, the blood-based $\mathrm{CL}_{\mathrm{H}, \mathrm{B}}\left(\mathrm{CL}_{\mathrm{H}} / \mathrm{R}_{\mathrm{B}}\right)$ value was capped at $90 \%$ of canine hepatic blood flow $(36 \mathrm{ml} / \mathrm{min} / \mathrm{kg})$. Differences in $\mathrm{CL}_{\mathrm{int}, \mathrm{H}}$ predicted from in vitro data relative to in vivo $\mathrm{CL}_{\mathrm{int}, \mathrm{H}}$ and the corresponding precision of the prediction were assessed by geometric mean fold error (gmfe, eq. 10) and the root mean square error (eq. 11) (Gertz et al., 2010), respectively:

$$
\begin{aligned}
& \text { gmfe }=10^{\frac{1}{N} \sum\left|\log \left(\frac{\text { predicted } \mathrm{CL}_{\text {int, } \mathrm{H}}}{\text { observed } \mathrm{CL}_{\mathrm{int}, \mathrm{H}}}\right)\right|} \\
& \text { rmse }=\sqrt{\frac{1}{N} \sum(\text { predicted }- \text { observed })^{2}}
\end{aligned}
$$

where $N$ indicates the number of drugs included in the analysis.

To evaluate whether dog as a preclinical species can improve prediction of hepatic uptake transporter-mediated clearance in humans, the gmfe obtained from dog IVIVE was applied as an $\mathrm{ESF}_{\mathrm{av}}$ in human predictions. In addition to $\mathrm{ESF}_{\mathrm{av}}$, the performance of human clearance prediction was assessed by using drugspecific ESF obtained from the ratio of observed to predicted clearance in dog for each individual drug $\left(\mathrm{ESF}_{\mathrm{sd}}\right.$ ) (Naritomi et al., 2001; Ito and Houston, 2005; De Bruyn et al., 2018). In addition to dog, the same strategy was applied using scalars obtained from the IVIVE of monkey and rat in vitro data obtained in plated hepatocytes and for the same set of OATP substrates. For monkey, the ESF values were taken from a previous publication (De Bruyn et al., 2018). In the case of rat, the ESFs were calculated from previously reported in vitro data in rat hepatocytes (Ménochet et al., 2012a; Cantrill and Houston, 2017) and literature-collated in vivo clearance values (details listed in Supplemental Table S4). The direct IVIVE of human clearance was performed using the mean of in vitro data from four donors of human hepatocytes for which OATP1B1 c.521T $>$ C genotype information was not known (Ménochet et al., 2012b; De Bruyn et al., 2018). Considering variability in transporter expression and/or activity in different lots of human hepatocytes, in vitro data from multiple donors were included in the evaluation. To assess the ability of preclinical species to refine prediction of human $\mathrm{CL}_{\mathrm{int}, \mathrm{H}}$, the predicted $\mathrm{CL}_{\mathrm{int}, \mathrm{H}}$ values in humans for nine OATP substrates were multiplied by either $\mathrm{ESF}_{\mathrm{av}}$ or $\mathrm{ESF}_{\mathrm{sd}}$ obtained from rat, dog (excluding bosentan, as data were not available), and monkey.

\section{Results}

Uptake Parameters in Dog Hepatocytes. A time-dependent increase in intracellular accumulation was observed for all nine drugs investigated. The mean uptake parameters obtained for individual drugs in three lots of dog hepatocytes are listed in Table 1; parameters obtained in each individual lot are summarized in Supplemental Table S5. A 15-fold range in $\mathrm{CL}_{\text {uptake }}$ was observed, with cerivastatin showing the highest $\mathrm{CL}_{\text {uptake }}\left(143 \pm 57 \mu \mathrm{l} / \mathrm{min} / 10^{6}\right.$ cells), followed by repaglinide, telmisartan, pitavastatin, and atorvastatin $\left(\mathrm{CL}_{\text {uptake }}>100 \mu \mathrm{l} / \mathrm{min} / 10^{6}\right.$ cells). In contrast, uptake was more than 10 -fold lower in the case of fexofenadine and pravastatin $\left(\mathrm{CL}_{\text {uptake }}<10 \mu \mathrm{l} / \mathrm{min} / 10^{6}\right.$ cells $)$. Drugs in the current data set showed a 35 -fold range in $\mathrm{CL}_{\text {passive }}$; cerivastatin and pravastatin showed the highest and lowest $\mathrm{CL}_{\text {passive }}$, respectively. The formation of non-P450 metabolites was minimal over a short incubation time, and rates of metabolism represented $0.4 \%, 6.6 \%$, and $9.9 \%$ of uptake rates of parent drugs for atorvastatin lactone, repaglinide glucuronide, and telmisartan glucuronide, respectively. Therefore, $\mathrm{CL}_{\text {int,met }}$ was not accounted for in the calculation of $\mathrm{CL}_{\text {active }}$. Overall, OATP substrates investigated in the current study showed $>65 \%$ contribution of the active transport to total uptake, with $5 / 9$ drugs having $>75 \%$ of active contribution (Table 1). The $\mathrm{CL}_{\text {active }}$ values of pitavastatin, pravastatin, rosuvastatin, and valsartan were previously reported using freshly isolated male dog hepatocytes in suspension with the temperature method $\left(37^{\circ} \mathrm{C}\right.$ vs. $\left.4^{\circ} \mathrm{C}\right)$ (Wilby et al., 2011). Their $\mathrm{CL}_{\text {active }}$ values were similar to those obtained in the present study, suggesting only a marginal effect of cryopreservation and plated format on hepatic uptake transporter activities in dog hepatocytes despite a difference in donors. Comparison of the $\mathrm{CL}_{\text {uptake }}, \mathrm{CL}_{\text {passive }}$, and $\mathrm{CL}_{\text {active }}$ values obtained in the individual donors of $\mathrm{dog}$ hepatocytes resulted in the overall good agreement (Supplemental Table S5), with most of the parameter values within 2-fold between individual donors with the exception of fexofenadine, where $\mathrm{CL}_{\text {uptake }}, \mathrm{CL}_{\text {passive, }}$, and $\mathrm{CL}_{\text {active }}$ showed differences across donors resulting in large $\mathrm{CV}$ on those parameters $(58 \%-93 \%)$. In

\section{TABLE 2}

Kp parameters of nine drugs investigated in dog hepatocytes

Data represent the mean $\pm S . D$. from three lots of dog hepatocytes. The $C L_{\text {int,met }}$ was determined from the slope of metabolite formation over time and was assumed to be equal to the $C L_{\text {int }}$ in eq. 2.

\begin{tabular}{lcccc}
\hline \multicolumn{1}{c}{ Drugs } & $\mathrm{Kp}$ & $\mathrm{CL}_{\text {int,met }}$ & $\mathrm{Kp}_{\text {uu }}$ & fu $_{\text {cell }}$ \\
\hline \multicolumn{5}{c}{$\mu \mathrm{l} / \mathrm{min} / 10^{6}$ cells } \\
Atorvastatin & $375 \pm 117$ & $1.94 \pm 0.37$ & $7.24 \pm 1.54$ & $0.021 \pm 0.007$ \\
Cerivastatin & $116 \pm 19$ & - & $3.34 \pm 0.74$ & $0.029 \pm 0.007$ \\
Fexofenadine & $38.5 \pm 10.7$ & - & $7.42 \pm 8.80$ & $0.168 \pm 0.170$ \\
Pitavastatin & $162 \pm 25$ & - & $3.81 \pm 1.37$ & $0.024 \pm 0.011$ \\
Pravastatin & $13.6 \pm 2.4$ & - & $9.54 \pm 4.83$ & $0.673 \pm 0.267$ \\
Repaglinide & $276 \pm 78$ & $24.8 \pm 10.9$ & $2.16 \pm 0.47$ & $0.008 \pm 0.002$ \\
Rosuvastatin & $26.4 \pm 3.9$ & - & $13.3 \pm 4.1$ & $0.509 \pm 0.157$ \\
Telmisartan & $308 \pm 108$ & $52.2 \pm 21.6$ & $1.62 \pm 0.22$ & $0.006 \pm 0.001$ \\
Valsartan & $307 \pm 159$ & - & $26.3 \pm 13.3$ & $0.097 \pm 0.064$ \\
\hline
\end{tabular}



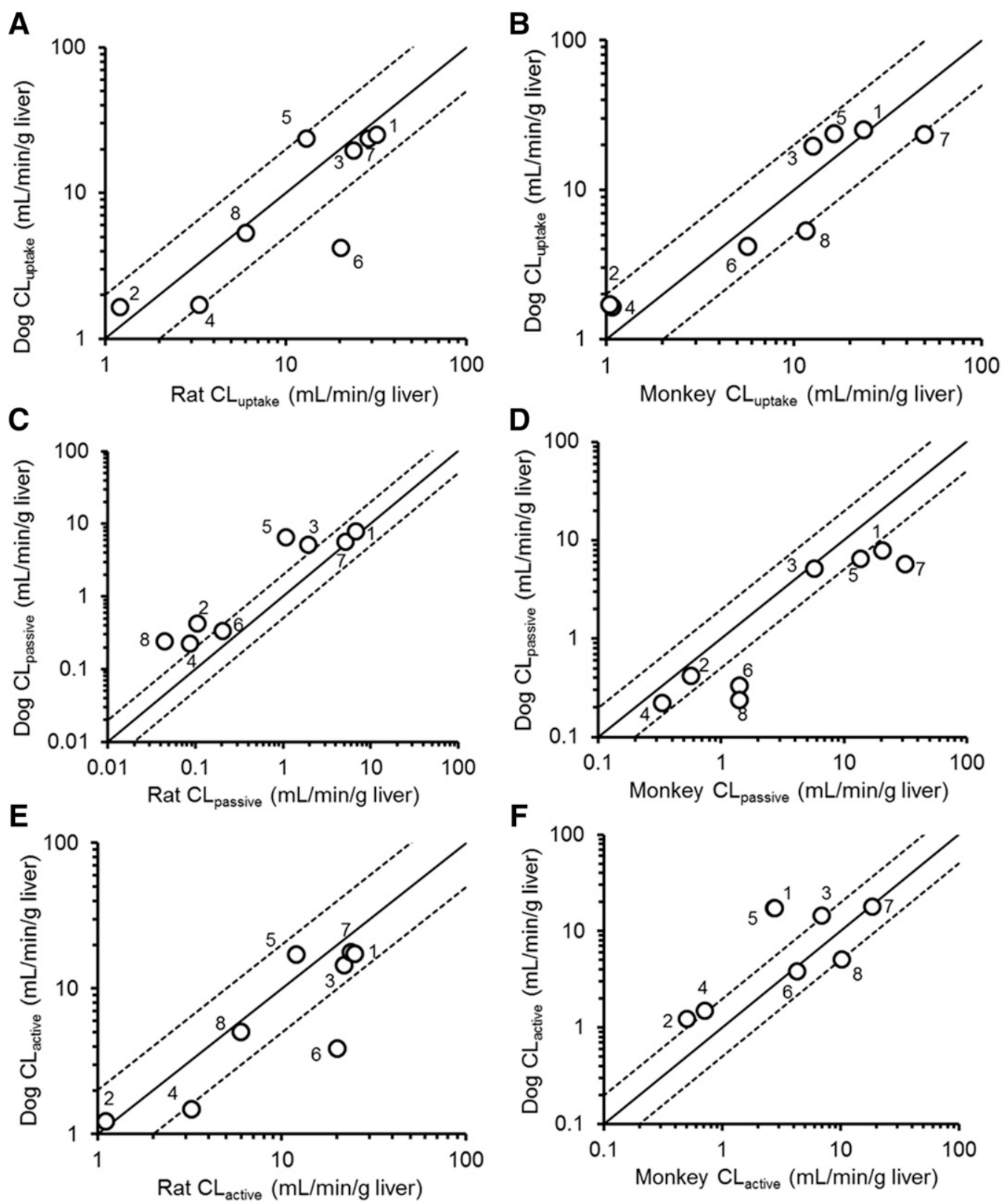

Fig. 2. Comparison of uptake parameters among species. $\mathrm{CL}_{\text {uptake }}(\mathrm{A}$ and $\mathrm{B}), \mathrm{CL}_{\text {passive }}(\mathrm{C}$ and $\mathrm{D})$, and $\mathrm{CL}_{\text {active }}(\mathrm{E}$ and $\mathrm{F})$ in plated dog hepatocytes were compared with those in rats (A, C, and E) (Ménochet et al., 2012a) and cynomolgus monkeys (B, D, and F) (De Bruyn et al., 2018). The solid and dashed lines represent the line of unity and 2-fold difference, respectively. 1, cerivastatin; 2, fexofenadine; 3, pitavastatin; 4, pravastatin; 5, repaglinide; 6 , rosuvastatin; 7, telmisartan; 8, valsartan.

addition to fexofenadine, pravastatin $\mathrm{CL}_{\text {passive }}$ showed a more than 3 -fold difference among donors.

The in vitro uptake parameters of eight drugs (cerivastatin, fexofenadine, pravastatin, pitavastatin, repaglinide, rosuvastatin, telmisartan, and valsartan) in dog hepatocytes were compared with those reported in human hepatocytes under similar experimental conditions (De Bruyn et al., 2018) (Fig. 1). In each case, a comparison was made between scaled parameters (expressed per gram of liver) due to differences in hepatocellularity between dog and human. The $\mathrm{CL}_{\text {uptake }}$ values obtained in dog hepatocytes were in good agreement with values in human hepatocytes, whereas the correlation of the $\mathrm{CL}_{\text {passive }}$ and $\mathrm{CL}_{\text {active }}$ values was less marked. Cerivastatin and telmisartan $\mathrm{CL}_{\text {passive values in human }}$ hepatocytes were approximately 3 -fold greater than values obtained in dog hepatocytes, whereas opposite trends were seen for pravastatin and valsartan (Table 1). In the case of $\mathrm{CL}_{\text {active, }}$, values for pravastatin, cerivastatin, fexofenadine, and valsartan were approximately 2- to 5-fold greater in dog hepatocytes.

Kp Parameters in Dog Hepatocytes. The Kp profiles over 90 minutes were investigated for all nine drugs in three donors of plated dog hepatocytes. Most of the drugs investigated reached steady state within 30 minutes except for fexofenadine and valsartan (Supplemental Fig. S1). The mean Kp parameters from three lots are shown in Table 2, and values obtained in each individual lot are summarized in Supplemental Table S6. A 28-fold range in mean $\mathrm{Kp}$ values was observed for the current data set, with values ranging from $13.6 \pm 2.4$ (pravastatin) to $375 \pm 117$ (atorvastatin). For six of the nine drugs, the Kp values were $>100$, with the exception of rosuvastatin, fexofenadine, and pravastatin. Analogous to the trends in uptake parameters, an overall good agreement was seen in $\mathrm{Kp}$ values obtained in different donors (within 3-fold difference); fexofenadine and pravastatin were again the outliers (Supplemental Table S6). 
TABLE 3

Pharmacokinetic parameters of nine drugs investigated following intravenous administration in dogs

Data represent the mean \pm S.D. from three male dogs intravenously infused. $C L_{H}$ was determined by subtracting $C L_{R}$ from $C L_{\text {total }}$.

\begin{tabular}{lccccc}
\hline \multicolumn{1}{c}{ Drugs } & \multicolumn{1}{c}{$\mathrm{CL}_{\text {total }}$} & $\mathrm{CL}_{\mathrm{R}}$ & $\mathrm{CL}_{\mathrm{H}}$ & $\mathrm{fu}_{\mathrm{p}}$ & $\mathrm{R}_{\mathrm{B}}$ \\
\hline & $\mathrm{ml} / \mathrm{min} / \mathrm{kg}$ & $\mathrm{ml} / \mathrm{min} / \mathrm{kg}$ & $\mathrm{ml} / \mathrm{min} / \mathrm{kg}$ & & \\
Atorvastatin & $48.4 \pm 13.3$ & $\mathrm{ND}$ & $48.4 \pm 13.3$ & $0.057 \pm 0.004$ & $0.55^{a}$ \\
Cerivastatin & $2.48 \pm 0.39$ & $\mathrm{ND}$ & $2.48 \pm 0.39$ & $0.021 \pm 0.001$ & $0.76^{b}$ \\
Fexofenadine & $4.67 \pm 1.42$ & $0.401 \pm 0.14$ & $4.27 \pm 1.30$ & $0.134 \pm 0.001$ & $0.55^{c}$ \\
Pitavastatin & $5.86 \pm 1.61$ & $\mathrm{ND}$ & $5.86 \pm 1.61$ & $0.014 \pm 0.002$ & $0.60^{d}$ \\
Pravastatin & $14.1 \pm 2.26$ & $5.66^{e}$ & $10.4 \pm 2.98$ & $0.498 \pm 0.02$ & $0.60^{d}$ \\
Repaglinide & $1.48 \pm 0.47$ & $\mathrm{ND}$ & $1.48 \pm 0.47$ & $0.003 \pm 0.0001$ & $0.48^{b}$ \\
Rosuvastatin & $23.2 \pm 3.77$ & $2.30 \pm 1.23$ & $20.9 \pm 2.83$ & $0.176 \pm 0.006$ & $0.56^{b}$ \\
Telmisartan & $17.4 \pm 3.46$ & $\mathrm{ND}$ & $17.4 \pm 3.46$ & $0.021 \pm 0.003$ & $1.18^{f}$ \\
Valsartan & $8.31 \pm 1.33$ & $0.475 \pm 0.24$ & $7.84 \pm 1.45$ & $0.010 \pm 0.001$ & $0.70^{d}$ \\
\hline
\end{tabular}

$\mathrm{ND}$, not determined $(<1 \%$ total dose detected in urine).

${ }^{a}$ Gertz et al. (2010).

${ }^{b}$ Jones et al. (2012).

${ }^{c}$ Watanabe et al. (2011)

${ }^{d}$ Wilby et al. (2011).

${ }^{e}$ No urine was collected in one of three animals; therefore, $\mathrm{CL}_{\mathrm{R}}$ is the mean of two animals.

${ }^{f}$ Deguchi et al. (2011).

UDP-glucuronosyltransferase-mediated $\mathrm{CL}_{\text {int,met }}$ values of atorvastatin, repaglinide, and telmisartan determined in the extended Kp experiments were at least $15 \%$ of their respective $\mathrm{CL}_{\text {passive }}$ values. Therefore, $\mathrm{CL}_{\text {int,met }}$ was considered when calculating the $\mathrm{Kp}_{\mathrm{uu}}$ for these three drugs (eq. 2). A 16-fold range was observed in $\mathrm{Kp}_{\mathrm{uu}}$ values among nine drugs. The $\mathrm{Kp}_{\mathrm{uu}}$ values of rosuvastatin and valsartan were $>10$, whereas cerivastatin, pitavastatin, repaglinide, and telmisartan showed $\mathrm{Kp}_{\mathrm{uu}}$ values $<5$. There was a large range in $\mathrm{fu}_{\mathrm{cell}}$ (122-fold) in dog hepatocytes; high intracellular binding was observed for atorvastatin, cerivastatin, pitavastatin, repaglinide, and telmisartan $\left(\mathrm{fu}_{\text {cell }}<0.05\right)$. In addition, $\mathrm{CL}_{\text {active }}, \mathrm{CL}_{\text {passive, }}$, and $\mathrm{fu}_{\mathrm{cell}}$ for six drugs were estimated by simultaneous fitting of uptake data (single low drug concentration) over an extended time course \pm OATP inhibitor cocktail. The estimates obtained by the mechanistic two-compartment model (Supplemental Table S7) were comparable to those calculated in the two-step analysis of data from short incubation and Kp experiments. The fitting of the mechanistic model to drug cell concentrations versus time ( \pm inhibitor) as well as goodness-of-fit plots are illustrated for rosuvastatin as a representative drug in Supplemental Fig. S2. The $\mathrm{CL}_{\text {passive }}$ and $\mathrm{fu}_{\text {cell }}$ values for the nine drugs investigated were strongly correlated with the respective $\log \mathrm{D}_{7.4}$ (Supplemental Fig. S3, A and B); a relationship was also noted between the extent of intracellular binding in dog hepatocytes and $\mathrm{fu}_{\mathrm{p}}$ for the drugs investigated (Supplemental Fig. S3C).

Species Differences in Uptake Parameters. The $\mathrm{CL}_{\text {uptake }}, \mathrm{CL}_{\text {passive }}$, and $\mathrm{CL}_{\text {active }}$ in dog hepatocytes were compared with the previously reported values in Sprague-Dawley rat, cynomolgus monkey, and human (Ménochet et al., 2012a,b; Cantrill and Houston, 2017; De Bruyn et al., 2018) (Fig. 2). Rat hepatocyte $\mathrm{CL}_{\text {uptake }}$ and $\mathrm{CL}_{\text {active }}$ values were generally in good agreement with those obtained in dogs, with rosuvastatin being an outlier in both cases (Fig. 2, A and E). Rat hepatocyte $\mathrm{CL}_{\text {passive }}$ values were similar to those in dog hepatocytes for cerivastatin, rosuvastatin, and telmisartan but were up to 6-fold smaller for the remaining drugs (Fig. 2C). Monkey hepatocyte total $\mathrm{CL}_{\text {uptake }}$ data showed a good agreement with dog hepatocyte data (Fig. 2B). In contrast to rat, $\mathrm{CL}_{\text {passive }}$ values obtained in monkey hepatocytes were either similar to the data in dog (fexofenadine, pitavastatin, and pravastatin) or almost 6-fold greater for the remaining drugs (Fig. 2D). An opposite trend was seen for $\mathrm{CL}_{\text {active }}$ in which data were either comparable between the two species (rosuvastatin, telmisartan, and valsartan) or up to approximately 6-fold smaller for the remaining drugs in monkey hepatocytes (Fig. 2F).

In Vivo Studies and Extrapolation of Dog In Vitro Transporter Data to In Vivo. The pharmacokinetic studies for the nine drugs investigated were conducted following a single intravenous infusion over 30 minutes to three male beagle dogs. The in vivo parameters obtained are shown in Table 3. The $\mathrm{CL}_{\text {total }}$ values ranged from $1.48 \pm$ $0.47 \mathrm{ml} / \mathrm{min} / \mathrm{kg}$ (repaglinide) to $48.4 \pm 13.3 \mathrm{ml} / \mathrm{min} / \mathrm{kg}$ (atorvastatin). Hepatic clearance was the major elimination mechanism in beagle dog for the drugs investigated, as $\mathrm{CL}_{\mathrm{R}}$ contributed $<40 \%$ to the $\mathrm{CL}_{\text {total }}$. Six drugs (cerivastatin, fexofenadine, pitavastatin, pravastatin, repaglinide, and valsartan) were classified as low clearance drugs in beagle dogs, as their hepatic blood clearance $\left(\mathrm{CL}_{\mathrm{H}, \mathrm{B}}\right)$ was $<30 \%$ of hepatic blood flow.

The prediction of hepatic clearance in dogs is shown in Fig. 3. Good agreement between predicted and observed $\mathrm{CL}_{\text {int, } \mathrm{H}}$ was observed, with a gmfe of 2.73 and $55 \%$ of values predicted within 2 -fold of the observed data. Subsequently, the gmfe obtained in dog IVIVE for this data set was applied to human IVIVE as an $\mathrm{ESF}_{\mathrm{av}}$ with the aim to assess whether information obtained in dog as a preclinical species can improve prediction of hepatic uptake transporter-mediated clearance in humans. In addition to dog, a similar exercise was carried out using $\mathrm{ESF}_{\mathrm{av}}$ obtained from IVIVE of rat and monkey in vitro data obtained for the same set of OATP substrates (Table 4). The in vitro and in vivo data of nine drugs investigated in rats, monkeys, and humans are summarized in Supplemental Tables S4, S8, and S9, respectively.

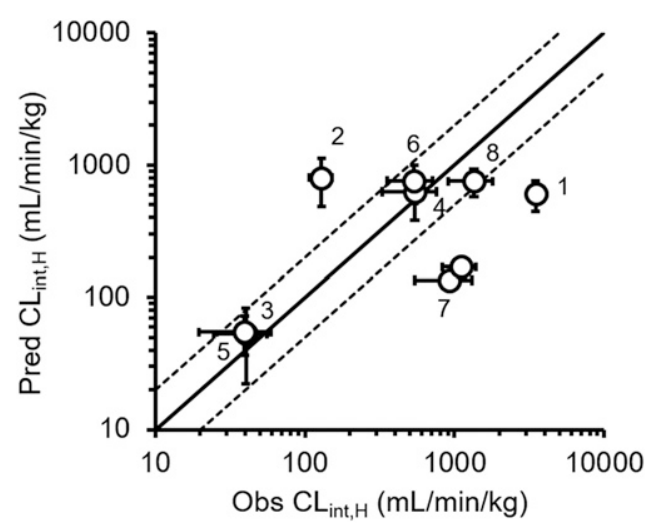

Fig. 3. Correlation of predicted and observed $\mathrm{CL}_{\mathrm{int}, \mathrm{H}}$ in dogs. Predicted $\mathrm{CL}_{\mathrm{int}, \mathrm{H}}$ values were compared with in vivo $\mathrm{CL}_{\mathrm{int}, \mathrm{H}}$ in dogs. Predicted and observed data represent the mean \pm S.D. of $n=3$. The solid and dashed lines represent the line of unity and 2-fold difference, respectively. 1, atorvastatin; 2, cerivastatin; 3 , fexofenadine; 4, pitavastatin; 5, pravastatin; 6 , repaglinide; 7, rosuvastatin; 8 , telmisartan; 9, valsartan. 
TABLE 4

Statistical data comparing the accuracy and precision of the use of species-related ESFs to predict human $\mathrm{CL}_{\mathrm{int}, \mathrm{H}}$

Direct method involved no use of ESFs, whereas ESF $F_{a v}$ and ESF $F_{\text {sd }}$ indicate the use of drug set average and individual drug specific ESFs, respectively.

\begin{tabular}{lccc}
\hline \multirow{2}{*}{ Parameters } & \multicolumn{2}{c}{ Species } \\
\cline { 2 - 4 } & $\operatorname{Dog}^{a}$ & Rat & Monkey \\
\hline Number of drugs & 8 & 9 & 9 \\
Direct & & & \\
gmfe & 3.44 & 3.22 & 3.22 \\
rmse & 3114 & 2936 & 2936 \\
\% within 2-fold error & 25 & 33 & 33 \\
ESF & & & \\
gmfe & 2.11 & 2.03 & 2.03 \\
rmse & 2497 & 2392 & 2377 \\
\% within 2-fold error & 50 & 56 & 56 \\
ESF & & & \\
gmfe & 3.23 & 3.41 & 2.96 \\
rmse & 2890 & 2957 & 67 \\
\% within 2-fold error & 25 & 22 & \\
\hline
\end{tabular}

rmse, root mean square error.

${ }^{a}$ Data set excludes bosentan in dog (includes the remaining drugs: rosuvastatin, pitavastatin, cerivastatin, pravastatin, telmisartan, valsartan, repaglinide, fexofenadine).

${ }^{b}$ The $\mathrm{ESF}_{\mathrm{av}}$ values obtained in the IVIVE of preclinical $\mathrm{CL}_{\text {uptake }}$ data were 2.73, 2.61, and 2.66 in $\mathrm{dog}$, rat, and monkey, respectively.

The direct prediction of human clearance from in vitro data (no ESF) resulted in underprediction of in vivo $\mathrm{CL}_{\text {int,H }}$ (3.22-fold bias, Fig. 4; Table 4). The improvement in prediction of human $\mathrm{CL}_{\mathrm{int}, \mathrm{H}}$ observed using $\mathrm{ESF}_{\mathrm{av}}$ was comparable across the three preclinical species, resulting in approximately 2-fold bias and increased precision (Fig. 5, A, $\mathrm{C}$, and $\mathrm{E}$; Table 4). This lack of difference in the prediction success among the $\mathrm{ESF}_{\mathrm{av}}$ from the three preclinical species is also reflected in the residual plots (Figs. 4C and 6). In contrast, the use of individual drug-specific scaling factors $\left(\mathrm{ESF}_{\mathrm{sd}}\right)$ resulted in species-selective effects on the predictive performance (Fig. 4D). There was no improvement in the prediction bias of human clearance using rat $\mathrm{ESF}_{\mathrm{sd}}$ (gmfe 3.41), with $<25 \%$ of the drugs falling within the 2-fold error (Fig. 5D; Table 4). Use of $\mathrm{ESF}_{\mathrm{sd}}$ obtained from dog and monkey data resulted in comparable bias (3.23- and 2.96-fold, respectively) with minor improvement in human clearance prediction. A higher proportion of drugs predicted within the 2-fold error was evident when monkey $\mathrm{ESF}_{\mathrm{sd}}$ was applied (67\%) relative to dog $\mathrm{ESF}_{\mathrm{sd}}(25 \%)$ (Fig. 5B and 5F, Fig. 6; Table 4).

Species Differences in Kp Parameters. Large interspecies differences were apparent between $\mathrm{Kp}$ and $\mathrm{Kp}_{\mathrm{uu}}$ (rank order of rat $>$ dog $>$ monkey seen for both parameters) (Fig. 7). Rat hepatocyte $\mathrm{Kp}$ and $\mathrm{Kp} \mathrm{pu}_{\mathrm{uu}}$ values were up to 23- and 7.4-fold larger than those in dog hepatocytes, respectively (Fig. 7, A and D). The exceptions were repaglinide, telmisartan, and valsartan $\mathrm{Kp}$ and cerivastatin and fexofenadine $\mathrm{Kp}_{\mathrm{uu}}$, which were comparable between the two species. In contrast, dog $\mathrm{Kp}$ and $\mathrm{Kp}$ uu were comparable or greater than the data obtained in monkey hepatocytes, with the exception of telmisartan $\mathrm{Kp}_{\mathrm{uu}}$ (Fig. 7, B and E). Differences in fexofenadine, pravastatin, and valsartan were particularly marked, as dog Kp parameters were up to 6.2-fold greater than values obtained in monkey. The overall trends seen between dog and monkey Kp parameters were also evident in the comparison of $\operatorname{dog}$ and human $\mathrm{Kp}$ and $\mathrm{Kp}_{\mathrm{uu}}$, with the exception of valsartan. Even though $\mathrm{Kp}$ and $\mathrm{Kp}_{\mathrm{uu}}$ showed speciesdependent values, there was a good agreement in intracellular binding parameter across species. This trend was particularly strong between dog and monkey fu $\mathrm{u}_{\text {cell }}$ data (1.76-fold bias), whereas 2.3- and 2.6-fold differences were seen in $\operatorname{dog} \mathrm{fu}_{\text {cell }}$ relative to rat and human data, respectively.

\section{Discussion}

The utility of the cynomolgus monkey as a preclinical species for OATP-mediated hepatic clearance has recently been demonstrated, and
A
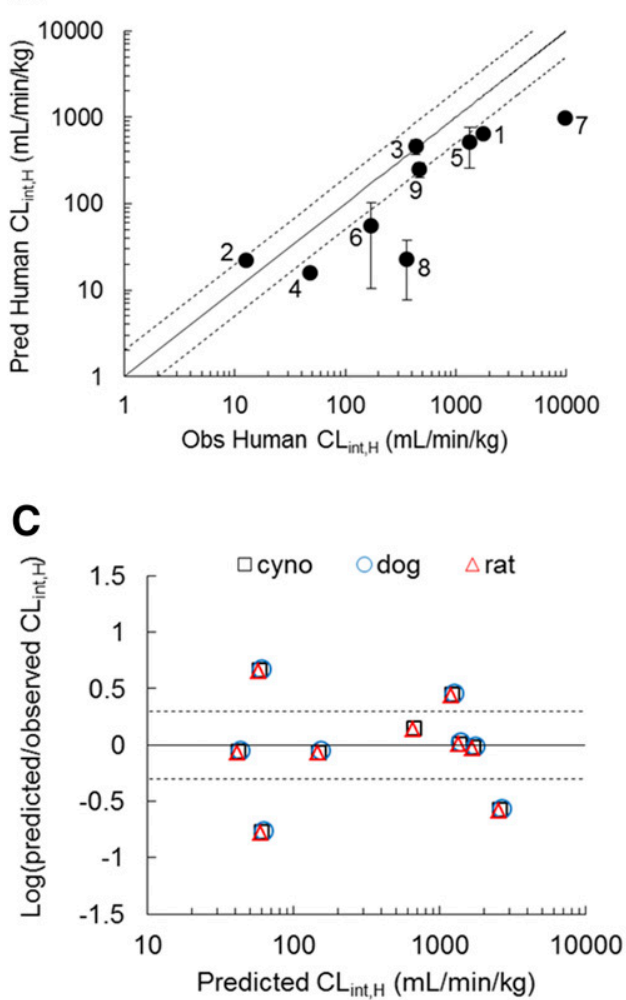

B
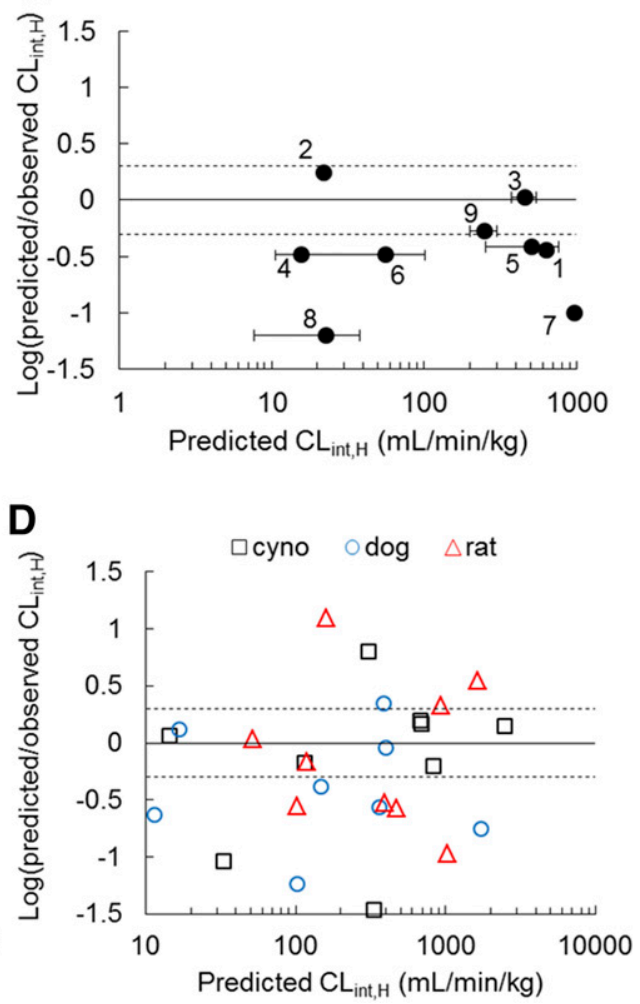

Fig. 4. Correlation of predicted and observed $\mathrm{CL}_{\text {int } \mathrm{H}}$ in humans in the absence of an empirical scaling factor (A, B), and direct comparison of the performance of ESFs from rat, dog, and monkey in improving human $\mathrm{CL}_{\mathrm{int}, \mathrm{H}}$ prediction (C, D). Predicted $\mathrm{CL}_{\text {int, } \mathrm{H}}$ values were compared with observed human $\mathrm{CL}_{\mathrm{int}, \mathrm{H}}(\mathrm{A})$ and to precision error expressed as the $\log$ of predicted/observed $\mathrm{CL}_{\text {int, } \mathrm{H}}$ ratio either in the absence $(\mathrm{B})$ or presence of drug set average $\left(\mathrm{ESF}_{\mathrm{av}}\right)(\mathrm{C})$ and individual drug-specific $\left(\mathrm{ESF}_{\mathrm{sd}}\right)$ (D) empirical scaling factors. Human hepatocyte data represent the mean \pm S.D. of $n=4$ donors (details in Supplemental Table S9 footnote). Error bars in (C and D) were excluded for clarity and distinction of preclinical species. The solid and dashed lines represent the line of unity and 2-fold difference, respectively. 1, cerivastatin; 2 , fexofenadine; 3 , pitavastatin; 4, pravastatin; 5 , repaglinide; 6 , rosuvastatin; 7 , telmisartan; 8 , valsartan; 9 , bosentan. 

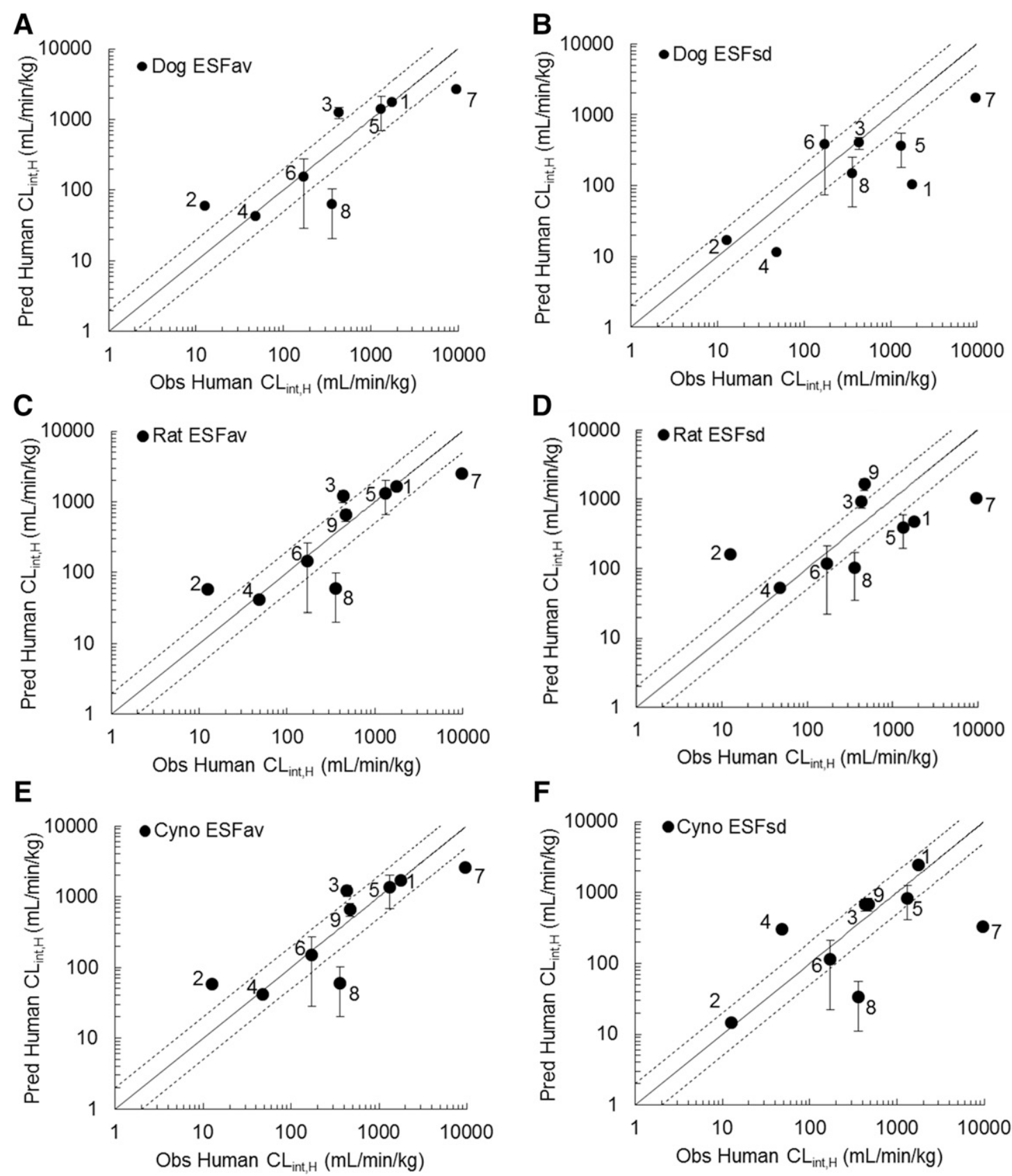

Fig. 5. Correlation of predicted and observed $\mathrm{CL}_{\mathrm{int}, \mathrm{H}}$ in humans using average and drug-specific empirical scaling factors obtained from rat, dog, and monkey. Predicted human $\mathrm{CL}_{\text {int.H }}$ values were compared with in vivo human $\mathrm{CL}_{\text {int.H }}$ following application of drug set average empirical scaling factors $\left(\mathrm{ESF}_{\mathrm{av}}\right)(\mathrm{A}, \mathrm{C}$, and $\mathrm{E})$, or individual drug-specific empirical scaling factors $\left(\mathrm{ESF}_{\mathrm{sd}}\right)(\mathrm{B}, \mathrm{D}$, and $\mathrm{F})$ from $\operatorname{dog}(\mathrm{A}$ and $\mathrm{B})$, rat $(\mathrm{C}$ and $\mathrm{D})$, and monkey $(\mathrm{E}$ and $\mathrm{F})$. Predicted and observed $\mathrm{CL}_{\mathrm{int}, \mathrm{H}}$ values in rats, monkeys, and humans were previously reported (Supplemental Tables S4, S8 and S9, respectively). Human hepatocyte data represent the mean \pm SD of $n=4$ donors (details in Supplemental Table S9 footnote). The solid and dashed lines represent the line of unity and 2-fold difference, respectively. 1, cerivastatin; 2, fexofenadine; 3, pitavastatin; 4 , pravastatin; 5, repaglinide; 6 , rosuvastatin; 7, telmisartan; 8 , valsartan; 9 , bosentan.

a good relationship between in vitro-derived clearance in hepatocytes and in vivo clearance was observed (De Bruyn et al., 2018). As reported for metabolism-related hepatic clearance predictions from hepatocytes (and other in vitro systems), underprediction of transporter-mediated clearance also requires a bias correction to bridge the gap between extrapolated and observed values. This approach, applied retrospectively, is regarded as empirical and hence has no mechanistic basis. Recently, application of the bias correction observed in the IVIVE of cynomolgus monkey clearance improved the prediction of human hepatic clearance for the same OATP substrates from human hepatocytes. Therefore, an analogous approach was applied here to two widely used preclinical species, beagle dog and
Sprague-Dawley rat. As a nonrodent preclinical species, beagle dogs are often used in pharmacokinetic studies; however, there is less information available to assess the predictive performance of hepatic transportermediated clearance and DDIs in this species compared with studies reported in cynomolgus monkeys (Shen et al., 2013; Chu et al., 2015; Watanabe et al., 2015; Ufuk et al., 2018). Therefore, characteristics of the hepatic uptake of a series of nine drugs were investigated to provide a data set of parameters for comparative purposes and evaluate beagle dogs as a preclinical animal model to study hepatic uptake.

In the present study, an OATP inhibitor cocktail was used to determine the $\mathrm{CL}_{\text {passive }}$ value in dog hepatocytes. Substrate-dependent inhibition 
A
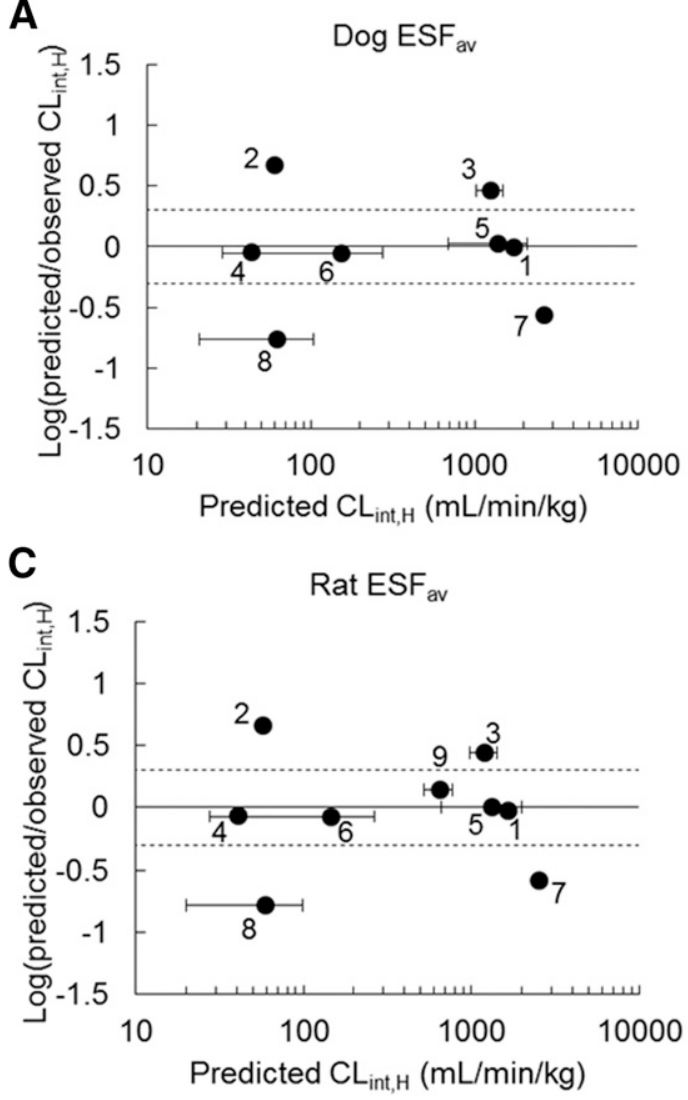

E

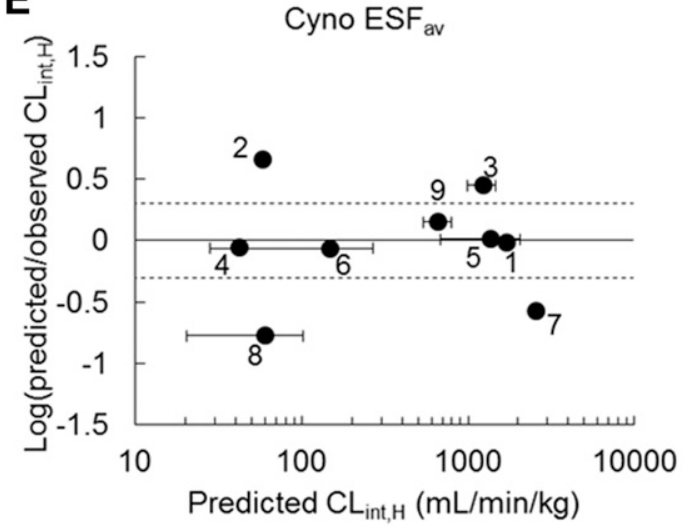

B

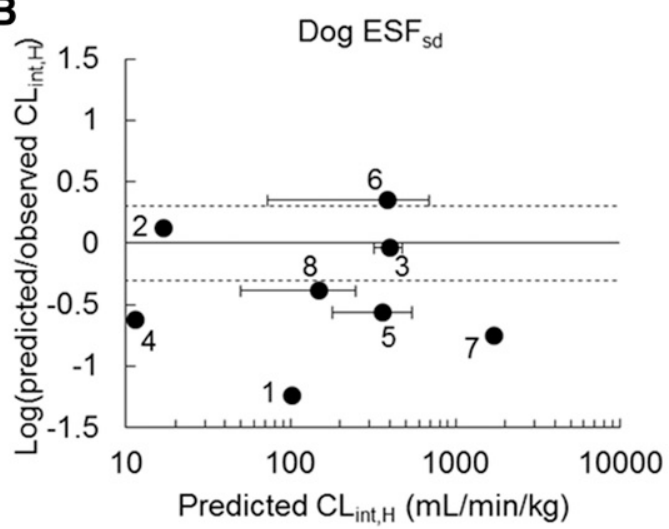

D

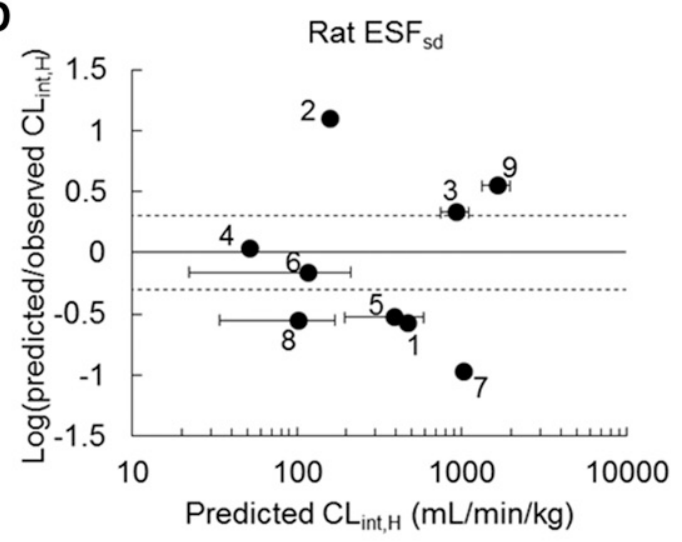

$\mathbf{F}$

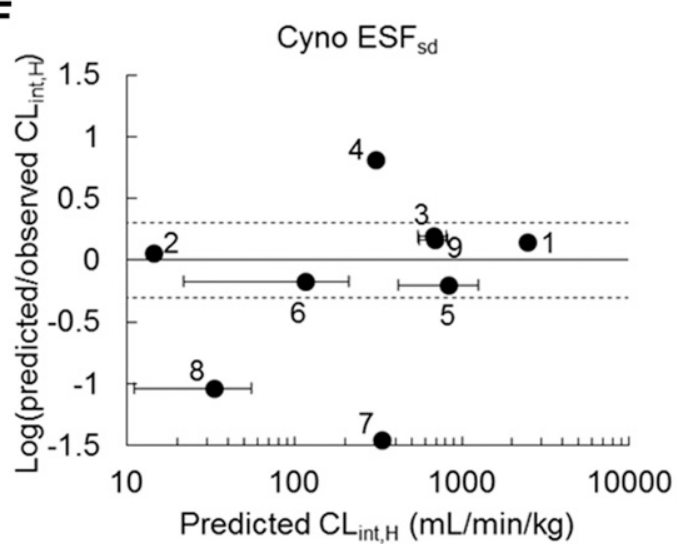

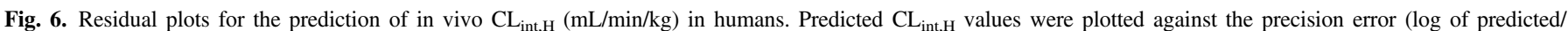

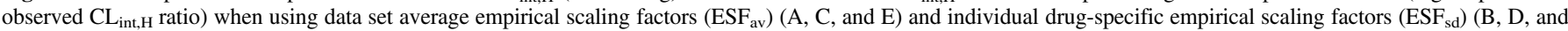

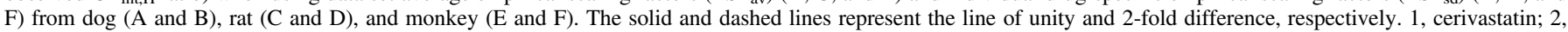
fexofenadine; 3, pitavastatin; 4, pravastatin; 5, repaglinide; 6 , rosuvastatin; 7 , telmisartan; 8 , valsartan; 9 , bosentan.

has been reported for human OATP1B1, OATP1B3, and OATP2B1 (Noé et al., 2007; Izumi et al., 2015; Barnett et al., 2018) and rationalized by multiple binding sites for substrates and inhibitors of OATP transporters. Accordingly, this may also be the case for canine Oatp1b4, and the use of multiple inhibitors for OATPs is preferable to determine the involvement of OATPs in hepatic uptake. Contributions of active uptake obtained here in dog hepatocytes (Table 1) were in good agreement with estimates previously reported in human hepatocytes (Ménochet et al., 2012b), suggesting a minimal difference in active uptake contribution to cellular uptake between humans and dogs for OATP substrates. Some interspecies differences in $\mathrm{CL}_{\text {passive }}$ values were apparent, with up to 2.5 -fold bias on average and an overall rank order of human $\geq$ monkey $>$ dog $>$ rat. These differences may be attributed to incomplete inhibition of active uptake in some species and/or the differences in the methodologies used to estimate this parameter [e.g., use of a single inhibitor (monkey and human), cocktail of inhibitors (dog), and mechanistic modeling (rat)]. However, for each species there was a good relationship with $\log \mathrm{D}_{7.4}$, consistent with other reports based on data obtained in transfected cell lines (Li et al., 2014).

Determining the extent of intracellular binding of drug in hepatocytes has important implications on understanding pharmacokinetic/ pharmacodynamic relationships, drug efficacy, and/or prediction of DDI risk (Zamek-Gliszczynski et al., 2013; Morse et al., 2015). Several experimental methods and in silico approaches to estimate intracellular drug concentration have been proposed (Chu et al., 2013; Guo et al., 2018), including the kinetic modeling used here. 
A
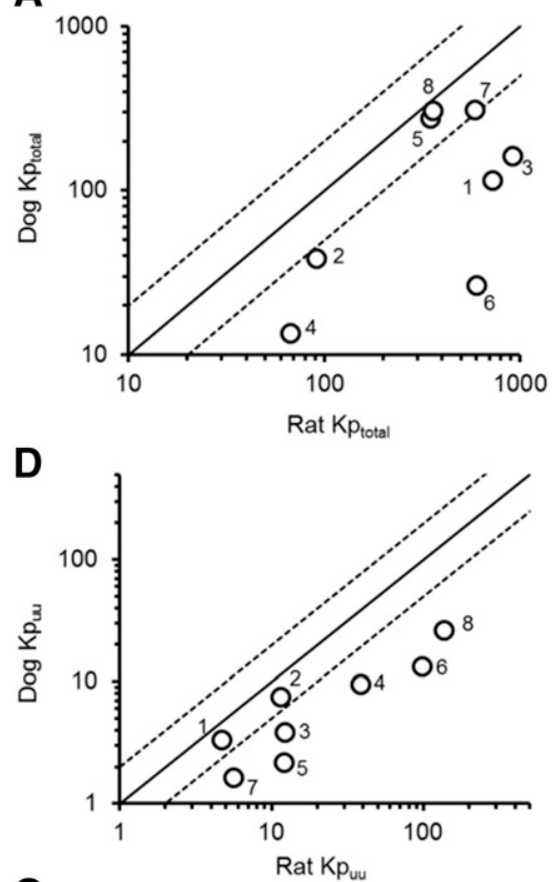

G

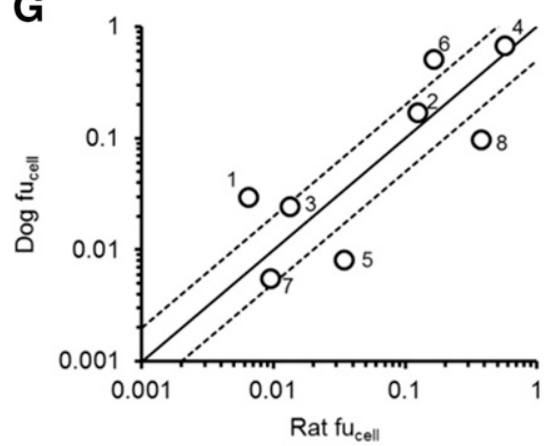

B

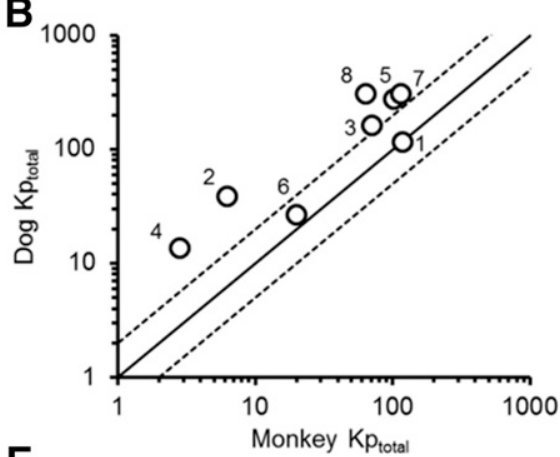

$E_{100}$
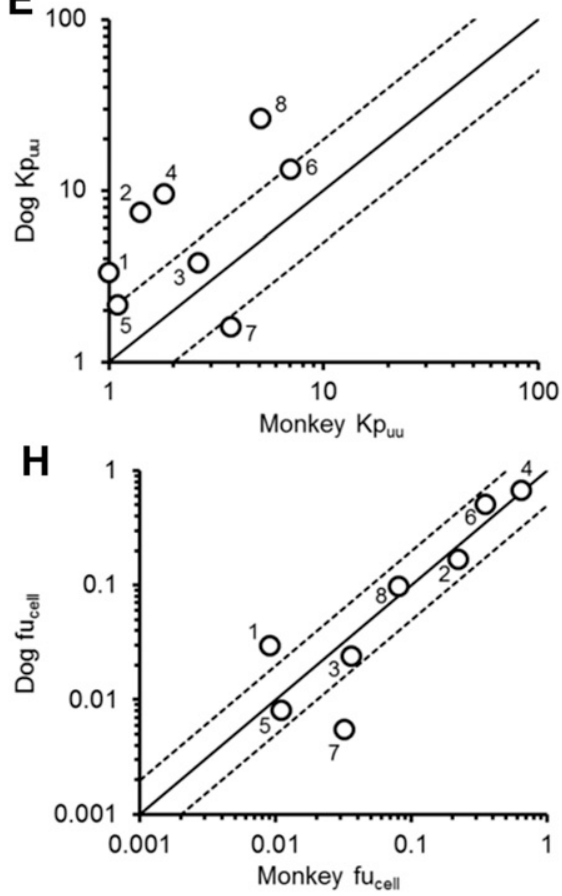

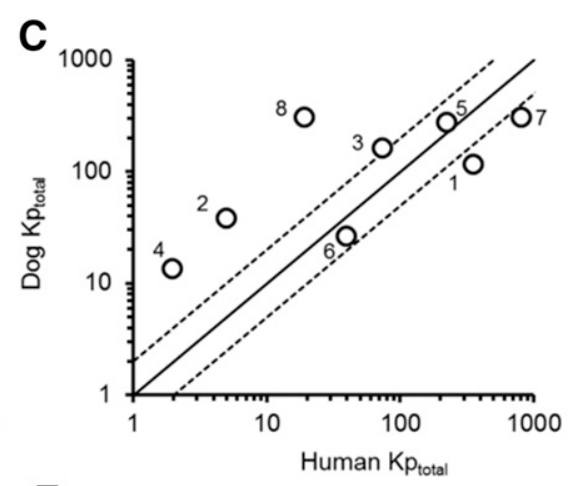

F
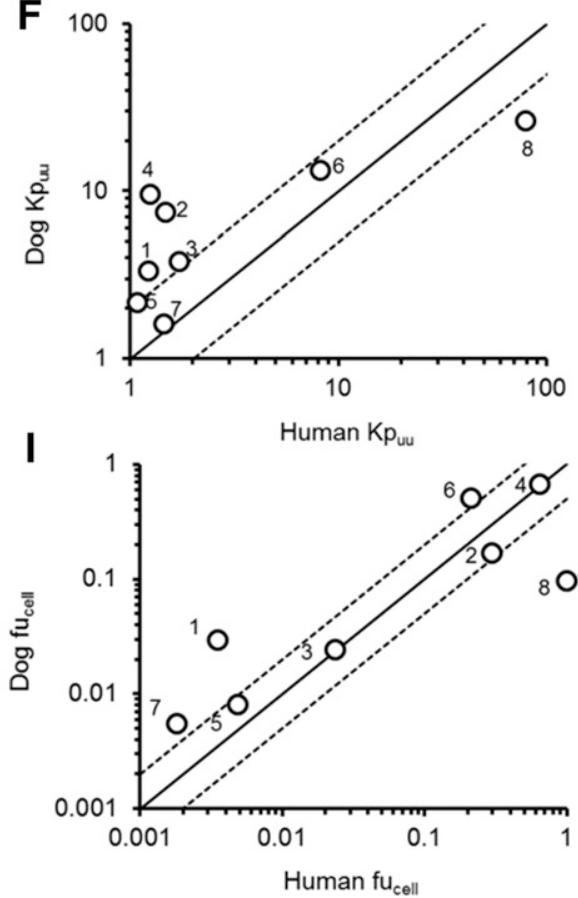

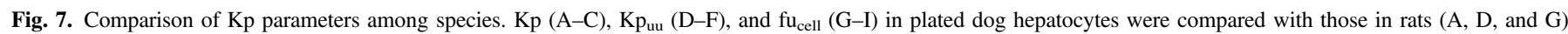

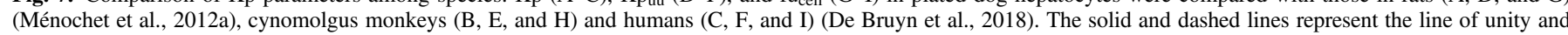
2-fold difference, respectively. 1, cerivastatin; 2, fexofenadine; 3, pitavastatin; 4, pravastatin; 5, repaglinide; 6, rosuvastatin; 7, telmisartan; 8, valsartan.

The $\mathrm{fu}_{\text {cell }}$ and $\mathrm{CL}_{\text {passive }}$ values obtained in plated dog hepatocytes for nine OATP substrates were strongly correlated with their $\log \mathrm{D}_{7.4}$ (Supplemental Fig. S3), consistent with previous studies in both suspended and plated rat hepatocytes (Yabe et al., 2011; Ménochet et al., 2012a), as well as plated monkey and human hepatocytes (De Bruyn et al., 2018). This trend is expected, as fu $\mathrm{u}_{\text {cell }}$ is inversely related to $\mathrm{Kp}$ when no active transport occurs. Estimation of hepatic fucell from the correlation to log $\mathrm{D}_{7.4}$ is well established and applicable for acidic compounds (Ménochet et al., 2012a; Chu et al., 2013) and provides a useful initial estimate of $\mathrm{fu}_{\text {cell }}$ in the case of limited data for implementation in the PBPK models. In addition, the current study showed a promising approach of simultaneous fitting of total uptake data \pm OATP inhibitors over a longer time period (up to steady state) using a single low drug concentration which yielded $\mathrm{fu}_{\text {cell }}$ estimates comparable to the indirect two-step method of the estimation of this parameter via $\mathrm{Kp}$ and $\mathrm{Kp}_{\mathrm{uu}}$.

Large interspecies differences were apparent in both $\mathrm{Kp}$ and $\mathrm{Kp}_{\mathrm{uu}}$ values, with the general rank order of rat $>\operatorname{dog}>$ cynomolgus monkey $\approx$ human for drugs investigated (Fig. 7, A-F). The $\mathrm{Kp}_{\mathrm{uu}}$ trends are not surprising, as this parameter reflects the interplay of active uptake and passive diffusion in addition to elimination processes (metabolism and biliary excretion). Interspecies differences in hepatic uptake clearance have been reported (Ménochet et al., 2012b; Watanabe et al., 2015) and correspond to some extent to differences in protein homology, but also to differences in absolute abundances of OATP/Oatp isoforms across species (Wang et al., 2015). Cynomolgus monkeys show 6- and 13-fold higher protein expressions of Oatp1b1 and Oatp1b3 compared with those in human OATP1B1 and OATP1B3, respectively, whereas comparable abundance is observed between dog Oatp1b4 and monkey Oatp1b1/Oatp1b3. In addition, the protein levels of rat Oatp1a1, Oatp1a4, and Oatp1b2 are lower than dog and monkey Oatps. In terms of the level of total protein (all OATP isoforms combined), the rank order is monkey $>$ rat $\gg$ dog $>$ human (Wang et al., 2015). Comparison of $\mathrm{CL}_{\text {active }}$ across species (Fig. 2, E and F) suggests that the interspecies differences of $\mathrm{Kp}_{\mathrm{uu}}$ cannot be explained solely by protein expression levels of OATP/Oatp in the liver, and that the interspecies differences in intrinsic transport affinity and capacity also need to be considered. Despite the discordance in $\mathrm{Kp}$ and $\mathrm{Kp}_{\mathrm{uu}}$ of drugs between hepatocytes from dog and other species, there was a good agreement in intracellular binding parameter fu $\mathrm{cell}_{\text {cell }}$ among dog, monkey, rat, and human (Fig. 7, G-I). These findings are in agreement with recent reports on correlations of $\mathrm{fu}_{\text {cell }}$ or $\mathrm{fu}_{\mathrm{liver}}$ between species for a diverse range of compounds (De Bruyn et al., 2018; Riccardi et al., 2018) and in relationships with $\log \mathrm{D}_{7.4}$ as a species-independent parameter. 
A 33-fold range was observed in $\mathrm{CL}_{\mathrm{H}}$ values in dog following a single intravenous infusion of nine drugs investigated; the $\mathrm{CL}_{\text {total }}$ or $\mathrm{CL}_{\mathrm{H}}$ values obtained in the present study were consistent with previous reports (pitavastatin $\mathrm{CL}_{\mathrm{H}}, 6.8 \mathrm{ml} / \mathrm{min} / \mathrm{kg}$; pravastatin $\mathrm{CL}_{\mathrm{H}}, 9.0 \mathrm{ml} / \mathrm{min} / \mathrm{kg}$; telmisartan $\mathrm{CL}_{\text {total }}, 6.75 \mathrm{ml} / \mathrm{min} / \mathrm{kg}$; valsartan $\mathrm{CL}_{\mathrm{H}}, 8.3 \mathrm{ml} / \mathrm{min} / \mathrm{kg}$ ) (Deguchi et al., 2011; Wilby et al., 2011). In vitro prediction in dogs resulted in a good agreement with in vivo values with a 2.73 -fold bias, and the predicted $\mathrm{CL}_{\mathrm{int}, \mathrm{H}}$ values of 5/9 drugs investigated within 2-fold of in vivo $\mathrm{CL}_{\mathrm{int}, \mathrm{H}}$ (Fig. 3). This drug set average scaling factor obtained in dog improved human IVIVE performance by reducing the prediction bias (to 2.11-fold) and increasing precision. Use of $\mathrm{ESF}_{\mathrm{av}}$ from other species resulted in a similar prediction success (2-fold bias in human IVIVE when using monkey and rat $\mathrm{ESF}_{\mathrm{av}}$ ). In contrast, use of $\mathrm{ESF}_{\mathrm{sd}}$ resulted in mixed success. Application of monkey $\mathrm{ESF}_{\mathrm{sd}}$ for human prediction resulted in a prediction bias of $<3$-fold, with $67 \%$ of drugs predicted within 2 -fold of the in vivo $\mathrm{CL}_{\mathrm{int}, \mathrm{H}}$ values. In contrast, both the prediction accuracy and the proportion of drugs within the same error threshold were lower using dog and rat drug-specific scalars (Figs. 4 and 5; Table 4). Although relatively smaller differences in drug-specific scaling factors (ratio of observed to predicted $\mathrm{CL}_{\mathrm{int}, \mathrm{H}}$ ) were observed between the species for a number of drugs (e.g., within 2.5-fold for repaglinide, telmisartan, and pitavastatin), the differences in $\mathrm{ESF}_{\mathrm{sd}}$ were more pronounced for pravastatin and cerivastatin (up to 27- and 4.6-fold larger in monkey and rat relative to the value obtained in dog, respectively). The present findings are based on a relatively small data set of well established OATP substrates; further studies with a larger number of transporter substrates, in particular with more challenging low-clearance OATP drugs and/or candidates with complex metabolism-transporter interplay, are required to establish wider application of the $\mathrm{ESF}_{\mathrm{sd}}$ method and confirm distinct trends between the preclinical species noted here. When using designated lots of human hepatocytes for assessment of new molecular entities, it would be prudent to evaluate uptake of a range of OATP substrates (low-medium-high clearance, different percentage of active vs. passive contribution to the overall uptake) to assess the need for ESF application from preclinical species.

In conclusion, the present study represents the most comprehensive assessment of OATP-mediated hepatic clearance performed to date in beagle dogs. In vitro uptake parameters obtained in this preclinical species showed low interindividual variability, with the exception of fexofenadine and pravastatin. Consistency in the extent of hepatocellular binding in three preclinical species and humans is encouraging and suggests that detailed mechanistic studies in preclinical species may be valuable to inform modeling of human hepatocyte data and subsequent PBPK model development. IVIVE of dog hepatocyte data resulted in a good agreement with the observed $\mathrm{CL}_{\mathrm{int}, \mathrm{H}}$ (2.73-fold bias). The use of this value as an average empirical scaling factor improved human clearance IVIVE, suggesting utility of beagle dog as a preclinical model for the assessment of hepatic uptake mediated by OATPs. Use of $\operatorname{dog} \mathrm{ESF}_{\mathrm{av}}$ resulted in success comparable to monkey in improving human IVIVE, in contrast to use of drug-specific scaling factors, rationalized by species differences in protein abundance and/or relative contribution of particular transporters to the overall hepatic uptake. Further investigations and expansion of the data set to include cationic drugs and assessment of DDIs associated with transportermediated uptake (in isolation or in conjunction with metabolism and biliary excretion) would be informative to strengthen the use of dog as a preclinical model for evaluation of transporter-mediated hepatic disposition.

\section{Acknowledgments}

We thank Dr. David Hallifax and Susan Murby for developing the methods of LC-MS/MS for the in vitro hepatocyte experiments.

\section{Authorship Contributions}

Participated in research design: Matsunaga, Morse, Hillgren, Hall, Houston, Galetin.

Conducted experiments: Matsunaga, Morse, Mohutsky, Bedwell, Bao.

Performed data analysis: Matsunaga, Ufuk, Morse.

Wrote or contributed to the writing of the manuscript: Matsunaga, Ufuk, Morse, Bedwell, Bao, Mohutsky, Hillgren, Hall, Houston, Galetin.

\section{References}

Barnett S, Ogungbenro K, Ménochet K, Shen H, Lai Y, Humphreys WG, and Galetin A (2018) Gaining mechanistic insight into coproporphyrin I as endogenous biomarker for OATP1Bmediated drug-drug interactions using population pharmacokinetic modeling and simulation. Clin Pharmacol Ther 104:564-574.

Bow DA, Perry JL, Miller DS, Pritchard JB, and Brouwer KL (2008) Localization of P-gp (Abcb1) and Mrp2 (Abcc2) in freshly isolated rat hepatocytes. Drug Metab Dispos 36:198-202.

Cantrill C and Houston JB (2017) Understanding the interplay between uptake and efflux transporters within in vitro systems in defining hepatocellular drug concentrations. J Pharm Sci 106: $2815-2825$.

Chu X, Korzekwa K, Elsby R, Fenner K, Galetin A, Lai Y, Matsson P, Moss A, Nagar S, Rosania GR, et al.; International Transporter Consortium (2013) Intracellular drug concentrations and transporters: measurement, modeling, and implications for the liver. Clin Pharmacol Ther 94: 126-141.

Chu X, Shih SJ, Shaw R, Hentze H, Chan GH, Owens K, Wang S, Cai X, Newton D, Castro-Perez $\mathrm{J}$, et al. (2015) Evaluation of cynomolgus monkeys for the identification of endogenous biomarkers for hepatic transporter inhibition and as a translatable model to predict pharmacokinetic interactions with statins in humans. Drug Metab Dispos 43:851-863.

De Bruyn T, Ufuk A, Cantrill C, Kosa RE, Bi YA, Niosi M, Modi S, Rodrigues AD, Tremaine LM, Varma MVS, et al. (2018) Predicting human clearance of organic anion transporting polypeptide substrates using cynomolgus monkey: in vitro-in vivo scaling of hepatic uptake clearance. Drug Metab Dispos 46:989-1000.

Deguchi T, Watanabe N, Kurihara A, Igeta K, Ikenaga H, Fusegawa K, Suzuki N, Murata S, Hirouchi M, Furuta Y, et al. (2011) Human pharmacokinetic prediction of UDP-glucuronosyltransferase substrates with an animal scale-up approach. Drug Metab Dispos 39:820-829.

Galetin A, Zhao P, and Huang SM (2017) Physiologically based pharmacokinetic modeling of drug transporters to facilitate individualized dose prediction. J Pharm Sci 106:2204-2208.

Gertz M, Cartwright CM, Hobbs MJ, Kenworthy KE, Rowland M, Houston JB, and Galetin A (2013) Cyclosporine inhibition of hepatic and intestinal CYP3A4, uptake and efflux transporters: application of PBPK modeling in the assessment of drug-drug interaction potential. Pharm Res 30:761-780.

Gertz M, Harrison A, Houston JB, and Galetin A (2010) Prediction of human intestinal first-pass metabolism of 25 CYP3A substrates from in vitro clearance and permeability data. Drug Metab Dispos 38:1147-1158.

Gill KL, Houston JB, and Galetin A (2012) Characterization of in vitro glucuronidation clearance of a range of drugs in human kidney microsomes: comparison with liver and intestinal glucuronidation and impact of albumin. Drug Metab Dispos 40:825-835.

Gui C and Hagenbuch B (2010) Cloning/characterization of the canine organic anion transporting polypeptide $1 \mathrm{~b} 4$ (Oatp1b4) and classification of the canine OATP/SLCO members. Comp Biochem Physiol C Toxicol Pharmacol 151:393-399.

Guo Y, Chu X, Parrott NJ, Brouwer KLR, Hsu V, Nagar S, Matsson P, Sharma P, Snoeys J, Sugiyama Y, et al.; International Transporter Consortium (2018) Advancing predictions of tissue and intracellular drug concentrations using in vitro, imaging and physiologically based pharmacokinetic modeling approaches. Clin Pharmacol Ther 104:865-889.

Heikkinen AT, Friedlein A, Matondo M, Hatley OJ, Petsalo A, Juvonen R, Galetin A, RostamiHodjegan A, Aebersold R, Lamerz J, et al. (2015) Quantitative ADME proteomics - CYP and UGT enzymes in the Beagle dog liver and intestine. Pharm Res 32:74-90.

Huang L, Berry L, Ganga S, Janosky B, Chen A, Roberts J, Colletti AE, and Lin MH (2010) Relationship between passive permeability, efflux, and predictability of clearance from in vitro metabolic intrinsic clearance. Drug Metab Dispos 38:223-231.

Ito K and Houston JB (2005) Prediction of human drug clearance from in vitro and preclinical data using physiologically based and empirical approaches. Pharm Res 22:103-112.

Izumi S, Nozaki Y, Maeda K, Komori T, Takenaka O, Kusuhara H, and Sugiyama Y (2015) Investigation of the impact of substrate selection on in vitro organic anion transporting polypeptide 1B1 inhibition profiles for the prediction of drug-drug interactions. Drug Metab Dispos 43:235-247

Jones HM, Barton HA, Lai Y, Bi YA, Kimoto E, Kempshall S, Tate SC, El-Kattan A, Houston JB Galetin A, et al. (2012) Mechanistic pharmacokinetic modeling for the prediction of transportermediated disposition in humans from sandwich culture human hepatocyte data. Drug Metab Dispos 40:1007-1017

Jones HM, Chen Y, Gibson C, Heimbach T, Parrott N, Peters SA, Snoeys J, Upreti VV, Zheng M, and Hall SD (2015) Physiologically based pharmacokinetic modeling in drug discovery and development: a pharmaceutical industry perspective. Clin Pharmacol Ther 97:247-262.

Li R, Bi YA, Lai Y, Sugano K, Steyn SJ, Trapa PE, and Di L (2014) Permeability comparison between hepatocyte and low efflux MDCKII cell monolayer. AAPS J 16:802-809.

Mahmood I (1998) Interspecies scaling of renally secreted drugs. Life Sci 63:2365-2371.

Ménochet K, Kenworthy KE, Houston JB, and Galetin A (2012a) Simultaneous assessment of uptake and metabolism in rat hepatocytes: a comprehensive mechanistic model. $J$ Pharmacol Exp Ther 341:2-15.

Ménochet K, Kenworthy KE, Houston JB, and Galetin A (2012b) Use of mechanistic modeling to assess interindividual variability and interspecies differences in active uptake in human and rat hepatocytes. Drug Metab Dispos 40:1744-1756.

Morse BL, Cai H, MacGuire JG, Fox M, Zhang L, Zhang Y, Gu X, Shen H, Dierks EA, Su H, et al (2015) Rosuvastatin liver partitioning in cynomolgus monkeys: measurement in vivo and prediction using in vitro monkey hepatocyte uptake. Drug Metab Dispos 43:1788-1794.

Naritomi Y, Terashita S, Kimura S, Suzuki A, Kagayama A, and Sugiyama Y (2001) Prediction of human hepatic clearance from in vivo animal experiments and in vitro metabolic studies with liver microsomes from animals and humans. Drug Metab Dispos 29:1316-1324. 
Noé J, Portmann R, Brun ME, and Funk C (2007) Substrate-dependent drug-drug interactions between gemfibrozil, fluvastatin and other organic anion-transporting peptide (OATP) substrates on OATP1B1, OATP2B1, and OATP1B3. Drug Metab Dispos 35:1308-1314.

Prueksaritanont T, Subramanian R, Fang X, Ma B, Qiu Y, Lin JH, Pearson PG, and Baillie TA (2002) Glucuronidation of statins in animals and humans: a novel mechanism of statin lactonization. Drug Metab Dispos 30:505-512.

Reinoso RF, Telfer BA, Brennan BS, and Rowland M (2001) Uptake of teicoplanin by isolated rat hepatocytes: comparison with in vivo hepatic distribution. Drug Metab Dispos 29:453-459.

Riccardi K, Ryu S, Lin J, Yates P, Tess D, Li R, Singh D, Holder BR, Kapinos B, Chang G, et al (2018) Comparison of species and cell-type differences in fraction unbound of liver tissues, hepatocytes, and cell lines. Drug Metab Dispos 46:415-421.

Säll C, Houston JB, and Galetin A (2012) A comprehensive assessment of repaglinide metabolic pathways: impact of choice of in vitro system and relative enzyme contribution to in vitro clearance. Drug Metab Dispos 40:1279-1289.

Shen H, Yang Z, Mintier G, Han YH, Chen C, Balimane P, Jemal M, Zhao W, Zhang R, Kallipatti $\mathrm{S}$, et al. (2013) Cynomolgus monkey as a potential model to assess drug interactions involving hepatic organic anion transporting polypeptides: in vitro, in vivo, and in vitro-to-in vivo extrapolation. J Pharmacol Exp Ther 344:673-685.

Shitara Y, Maeda K, Ikejiri K, Yoshida K, Horie T, and Sugiyama Y (2013) Clinical significance of organic anion transporting polypeptides (OATPs) in drug disposition: their roles in hepatic clearance and intestinal absorption. Biopharm Drug Dispos 34:45-78.

Ufuk A, Kosa RE, Gao H, Bi YA, Modi S, Gates D, Rodrigues AD, Tremaine LM, Varma MVS, Houston JB, et al. (2018) In vitro-in vivo extrapolation of OATP1B-mediated drug-drug interactions in cynomolgus monkey. J Pharmacol Exp Ther 365:688-699.

Varma MV, Steyn SJ, Allerton C, and El-Kattan AF (2015) Predicting clearance mechanism in drug discovery: extended clearance classification system (ECCS). Pharm Res 32:3785-3802.

Wang L, Prasad B, Salphati L, Chu X, Gupta A, Hop CE, Evers R, and Unadkat JD (2015) Interspecies variability in expression of hepatobiliary transporters across human, dog, monkey, and rat as determined by quantitative proteomics. Drug Metab Dispos 43:367-374.

Watanabe M, Watanabe T, Yabuki M, and Tamai I (2015) Dehydroepiandrosterone sulfate, a useful endogenous probe for evaluation of drug-drug interaction on hepatic organic anion transporting polypeptide (OATP) in cynomolgus monkeys. Drug Metab Pharmacokinet 30:198-204.
Watanabe T, Kusuhara H, Watanabe T, Debori Y, Maeda K, Kondo T, Nakayama H, Horita S, Ogilvie BW, Parkinson A, et al. (2011) Prediction of the overall renal tubular secretion and hepatic clearance of anionic drugs and a renal drug-drug interaction involving organic anion transporter 3 in humans by in vitro uptake experiments. Drug Metab Dispos 39: $1031-1038$.

Wilby AJ, Maeda K, Courtney PF, Debori Y, Webborn PJ, Kitamura Y, Kusuhara H, Riley RJ, and Sugiyama Y (2011) Hepatic uptake in the dog: comparison of uptake in hepatocytes and human embryonic kidney cells expressing dog organic anion-transporting polypeptide 1B4. Drug Metab Dispos 39:2361-2369.

Wood FL, Houston JB, and Hallifax D (2017) Clearance prediction methodology needs fundamental improvement: trends common to rat and human hepatocytes/microsomes and implications for experimental methodology. Drug Metab Dispos 45:1178-1188.

Yabe Y, Galetin A, and Houston JB (2011) Kinetic characterization of rat hepatic uptake of 16 actively transported drugs. Drug Metab Dispos 39:1808-1814.

Yoshida K, Zhao P, Zhang L, Abernethy DR, Rekić D, Reynolds KS, Galetin A, and Huang SM (2017) In vitro-in vivo extrapolation of metabolism- and transporter-mediated drug-drug interactions-overview of basic prediction methods. J Pharm Sci 106:2209-2213.

Yoshikado T, Toshimoto K, Nakada T, Ikejiri K, Kusuhara H, Maeda K, and Sugiyama Y (2017) Comparison of methods for estimating unbound intracellular-to-medium concentration ratios in rat and human hepatocytes using statins. Drug Metab Dispos 45:779-789.

Zamek-Gliszczynski MJ, Lee CA, Poirier A, Bentz J, Chu X, Ellens H, Ishikawa T, Jamei M, Kalvass JC, Nagar S, et al.; International Transporter Consortium (2013) ITC recommendations for transporter kinetic parameter estimation and translational modeling of transport-mediated PK and DDIs in humans. Clin Pharmacol Ther 94:64-79.

Address correspondence to: Dr. Aleksandra Galetin, Centre for Applied Pharmacokinetic Research, School of Health Sciences, The University of Manchester, Stopford Building, Oxford Road, Manchester M13 9PT, UK. E-mail: Aleksandra.Galetin@manchester.ac.uk 